\title{
Uma nova espécie de Sigara Fabricius (Hemiptera, Heteroptera, Corixidae) e redescrição das espécies do gênero com registro no Estado do Rio Grande do Sul, Brasil
}

\author{
Larissa P. Bernardo ${ }^{1}$; José Ricardo I. Ribeiro²; Cristina Stenert ${ }^{3} \&$ Leonardo Maltchik ${ }^{3}$
}

\begin{abstract}
${ }^{1}$ Universidade Federal de Santa Maria, Camobi, Av. Roraima, 1000, 97105-900 Santa Maria-RS, Brasil. larissap.bernardo@gmail.com
${ }^{2}$ Universidade Federal do Pampa, Campus São Gabriel, Av. Antônio Trilha, 1847, 97300-000 São Gabriel-RS, Brasil. joseribeiro@unipampa.edu.br (Corresponding author).

${ }^{3}$ Laboratório de Ecologia e Conservação de Ecossistemas Aquáticos, Universidade do Vale do Rio dos Sinos, Av. Unisinos, 950, $93022-000$ Cristo Rei, São Leopoldo-RS, Brasil. cstenert@unisinos.br; maltchik@unisinos.br
\end{abstract}

\begin{abstract}
A new species of Sigara Fabricius (Hemiptera, Heteroptera, Corixidae) and redescription of the species recorded in the State of Rio Grande do Sul, Brazil. Water boatmen (Corixidae) constitute the largest group of water bugs, with well over 40 species occurring in Brazil. Most of the species of Sigara are known from the Neotropics, and 11 of them have been reported in Brazil. Little is known about the distribution and taxonomy of Sigara species of Rio Grande do Sul. The following seven species are recorded and redescribed: Sigara (Tropocorixa) chrostowskii, S. (T.) denseconscripta, S. (T.) dita, S. (T.) hungerfordi, S. (T.) platensis, S. (T.) schadei, and S. (T.) townsendi. Sigara (T.) dita, S. (T.) hungerfordi, and $S$. (T.) townsendi are newly recorded from this State, while $S$. (T.) schadei is recorded for the first time from Brazil. Sigara (T.) bachmanni, sp. nov. is described from northeastern Rio Grande do Sul. This species resembles $S$. (T.) hungerfordi in having the synthlipsis less than 0.9 times the width of an eye, metaxyphus broader than long, and the infraocular portion of genae slender, but can be readily recognized by the presence of a short hook at apex of right clasper and serrations along the margin of its pre-apical portion. A key to the species of Sigara occurring in Rio Grande do Sul is provided. Although the general aspect of right clasper and the number of pegs of male pala as well as its shape have proven useful for species delimitation, $S$. (T.) chrostowskii and $S$. (T.) townsendi have shown considerable variation in these features and have been redescribed here.
\end{abstract}

KEYWORDS: Aquatic insects; male genitalia; Nepomorpha; southern Brazil.

RESUMO. Uma nova espécie de Sigara Fabricius (Hemiptera, Heteroptera, Corixidae) e redescrição das espécies do gênero com registro no Estado do Rio Grande do Sul, Brasil. Os corixídeos representam o maior grupo de percevejos aquáticos conhecido, com cerca de 40 espécies ocorrentes no Brasil. Grande parte das espécies de Sigara ocorre na Região Neotropical, 11 delas foram registradas no Brasil até o momento. A distribuição e taxonomia das espécies ocorrentes no Rio Grande do Sul são pouco conhecidas. Sete espécies foram registradas e redescritas: Sigara (Tropocorixa) chrostowskii, S. (T.) denseconscripta, S. (T.) dita, S. (T.) hungerfordi, $S$. (T.) platensis, $S$. (T.) schadei e $S$. (T.) townsendi. Três espécies foram registradas pela primeira vez no Estado: $S$. (T.) dita, S. (T.) hungerfordi e $S$. (T.) townsendi. Sigara (T.) schadei nunca tinha sido registrada no Brasil. Sigara (T.) bachmanni, sp. nov. é descrita com base em exemplares coletados no nordeste do Estado. Essa nova espécie é similar à $S$. (T.) hungerfordi por apresentar o comprimento do sintilipso menor que 0,9 vezes a largura de um olho, o metaxifo mais largo que comprido e a gena estreita; pode ser distinguida das demais pela presença de um gancho curto no ápice do parâmero direito dos espécimes do sexo masculino e pela presença da margem da região preapical denteada. Uma chave de identificação para as espécies de Sigara ocorrentes no Rio Grande do Sul é fornecida. Apesar das características relativas ao aspecto geral do parâmero direito e do número de espinhos e forma da pala serem usados na definição das espécies, $S$. (T.) chrostowskii e $S$. (T.) townsendi mostraram consideráveis variações nessas características e foram redescritas neste estudo.

PALAVRAS-CHAVE. Corixídeos; genitália masculina; insetos aquáticos; Nepomorpha; sul do Brasil.

A família Corixidae Leach, 1815 compreende cinco subfamílias, e duas delas (Heterocorixinae Hungerford, 1948 e Corixinae Enderlein, 1912) apresentam representantes na América do Sul (Nieser 1970). No que concerne à infraordem Nepomorpha, essa família apresenta o maior número de espécies descritas, e o Brasil é o país com grande parcela desses registros, além de possuir representantes de quatro dos oito gêneros estabelecidos (Centrocorisa Lundblad, 1928, Heterocorixa White, 1879, Sigara Fabricius, 1775, e Trichocorixa Kirkaldy, 1908), totalizando 30 espécies registradas (Heckman, 2011; Moreira et al., 2011). Entre- tanto, tanto Heckman (2011) como Moreira et al. (2011) não consideraram Micronectinae Jaczewski, 1924 elevada para o status de família, mas sim como subfamília de Corixidae, e o total de subfamílias e espécies de Corixidae estimado por esses autores não está correto. Micronectidae foi elevada para status de família por Nieser (2002) e atualmente apresenta cerca de 150 espécies descritas, compreendendo cinco gêneros (Nieser \& Chen 2006).

O gênero Sigara compreende 70 espécies, todas registradas exclusivamente nas Américas. Exceto pela espécie $S$. (Aphelosigara) tucma Bachmann,1961, todas as outras com 
representantes ocorrentes na América do Sul compreendem o subgênero Tropocorixa (Heckman, 2011). O Brasil apresenta 10 delas (conforme Moreira et al., 2011): S. (T.) braziliensis Hungerford, 1948, S. (T.) chrostowskii Jaczewski, 1927, S. (T.) czakii Jaczewski, 1927, S. (T.) denseconscripta (Breddin, 1897), S. (T.) denseconscriptoidea (Hungerford, 1928), S. (T.) dita Jaczewski, 1927, S. (T.) hungerfordi Jaczewski, 1927, S. platensis (T.) Bachmann, 1962, S. (T.) roberti Hungerford, 1948, S. (T.) townsendi (Hungerford, 1928). Heckman (2011: 341) cita $S$. (T.) trimaculata (Le Guillou,1841) como uma espécie ocorrendo no Rio Grande do Sul. Segundo Bachmann (1981), entretanto, esse registro foi baseado em indivíduos do sexo feminino e, devido à dificuldade em se identificá-los, é considerado duvidoso. Essa espécie, assim, não é contabilizada neste estudo.

No Rio Grande do Sul foram registrados, até o momento, as seguintes espécies de Corixidae: $S$. (T.) chrostowskii Jaczewski, 1927, S. (T.) denseconscripta (Breddin, 1897) e S. (T.) platensis Bachmann, 1962 (Hungerford 1948; Kleerekoper 1955; Nieser \& Melo 1997; Melo \& Nieser 2004; Heckman, 2011 não registra $S$. (T.) denseconscripta no Brasil), Trichocorixa mendozana Jaczewski, 1933 (Morrone et al. 2004; Heckman, 2011 menciona a existência de duas subespécies e é provável que seja T. mendozana mendozana Jaczewski, 1933) e uma espécie não identificada de Centrocorisa Lundblad, 1928 (Neri et al. 2005; possivelmente C. kollari (Fieber, 1851) conforme Heckman, 2011) da subfamília Corixinae; e Tenagobia (Fuscagobia) fuscata (Stål, 1859) (Nieser 1977) e T. (Incertagobia) incerta Lundblad, 1928 (Heckman, 2011) da subfamília Micronectinae.

Só recentemente listas faunísticas acerca dos heterópteros aquáticos ocorrentes no Brasil estão tornando-se comuns. Pode-se constatar um incremento no registro de Corixidae na lista seguinte de trabalhos publicados sobre o tema: Nieser \& Melo (1997), Vianna \& Melo (2003), Melo \& Nieser (2004), Neri et al. (2005), Pelli et al. (2006), Souza et al. (2006), Pereira \& Melo (2007), e Ribeiro et al. (2009). Registros sobre heterópteros aquáticos no Brasil estão dispersos na literatura, sendo raros os estudos sobre levantamentos regionais de espécies, sua ecologia, bem como o relacionamento de parentesco entre esses organismos (Nieser \& Melo 1997; Pereira et al. 2007). Como reflexo disso, o conhecimento da fauna do Estado do Rio Grande do Sul, bem como a quantidade de profissionais envolvidos com pesquisas nessas áreas, são incipientes. Na Região Sul, há uma ligeira concentração de registros de espécies em Santa Catarina, e isso pode ser explicado pelos esforços de coleta no passado de F. Plaumann no começo do século XX, especialmente em Nova Teutônia (Moreira et al. 2011). Expedições de coleta no Paraná resultaram nos primeiros registros de variação morfológica ocorrente no formato do parâmero direito dos representantes do sexo masculino de algumas espécies de Sigara (Jaczewski 1927, 1928).

Em áreas estudadas consideradas limítrofes ao Rio Grade do Sul, o número total de registros assinalados de espécies de Sigara ultrapassa o de registros no Brasil. O Uruguai e a Argentina juntos possuem 18 espécies registradas, e $S$. (T.) argentiniensis Hungerford, 1948, S. (T.) egbertae Hungerford, 1948, S. (T.) femoridens Hungerford, 1939, S. (T.) jensenhaarupi Jaczewski, 1927, S. (T.) hosfordae (Hungerford, 1928), $S$. (T.) rehi Jaczewski, 1930, S. (T.) rubiae (Hungerford, 1928), S. (T.) santiagiensis (Hungerford, 1928), S. (T.) schadei (Hungerford, 1928), S. (T.) trimaculata (Le Guillou, 1841), S. (T.) vuriloche Bachmann, 1960 e $S$. (T.) yala Bachmann, 1980 são as espécies que não são registradas no Brasil.

Os integrantes de Sigara possuem grande similaridade morfológica, sendo diferenciadas apenas pelo formato da genitália dos espécimes do sexo masculino. Entretanto foram comumente observadas e descritas variações inter- e intra-específicas em $S$. (T.) chrostowskii, S. (T.) czakii, S. (T.) dita e $S$. (T.) hungerfordi (Jaczewski 1927; Hungerford 1948; Bachmann 1981). Por exemplo, representantes do sexo masculino de $S$. (T.) chrostowskii e de $S$. (T.) townsendi apresentam semelhanças no aspecto de seu parâmero direito, com poucas variações no formato e no número de dentes da região preapical dessa estrutura, sendo de três a sete dentes na primeira e superior a sete na segunda (Hungerford 1948). Bachmann (1981) redescreveu a espécie $S$. (T.) chrostowskii, com base em espécimes da Argentina e discutiu a validade de $S$. (T.) townsendi, sugerindo inclusive a sinonímia entre essas espécies.

Neste trabalho, é apresentado pela primeira vez, o levantamento e a redescrição das espécies de Sigara com registro no Estado do Rio Grande do Sul. Durante o estudo, uma nova espécie foi encontrada proveniente do Município de São Francisco de Paula. Foram incluídas notas taxonômicas, uma chave de identificação para as espécies ocorrentes no Estado e mapas de distribuição das espécies. Além disso, foram estudadas e ilustradas as variações intra-específicas observadas no formato do parâmero direito, no número de espinhos da pala e no número de faixas do estrigilo na genitália dos espécimes do sexo masculino de $S$. (T.) chrostowskii e $S$. (T.) townsendi.

\section{MATERIAL E MÉTODOS}

Foram usados para este trabalho cerca de 150 exemplares adultos. O material estudado é proveniente de coleções do Laboratório de Biodiversidade do Pampa, Universidade Federal do Pampa, São Gabriel, Brasil (LEBIP), Universidade Federal de Santa Maria, Santa Maria, Brasil (UFSM) e Universidade do Vale do Rio dos Sinos, São Leopoldo, Brasil (UNISINOS). Os seguintes acrônimos foram citados na subseção "Informações sobre o tipo": Polish Museum of Natural History, Varsóvia, Polônia (PMNH); Snow Entomological Museum, University of Kansas, Lawrence, Estados Unidos (SEMC); Zoologisches Museum der Universität Hamburg (ZMH), Hamburgo, Alemanha. Os acrônimos foram estabelecidos conforme Arnett-JR. et al. (1993), exceto LEBIP, PMNH, UFSM, UNISINOS e ZMH.

A citação do material examinado e as localidades na subseção "Distribuição geográfica no Brasil" estão em ordem alfabética. O material examinado foi apresentado em 
texto corrido e adotaram-se vírgulas para separar as diferentes informações de um mesmo espécime (localidade, coordenada geográfica, tipo de ambiente, data de coleta, coletor e identificador, caso houvesse), informações entre parênteses para indicar os coletores e as instituições que armazenam as respectivas coleções de insetos e ponto-e-vírgulas no caso dos espécimes conterem informações iguais - para separar um espécime do outro. Eventualmente, pontos de interrogação foram usados para indicar dúvidas na grafia ou na localização precisa do material. Ainda na listagem, a letra "m" é referente ao sexo masculino e "f" ao sexo feminino. $\mathrm{O}$ item "tipo de ambiente" refere-se a uma breve caracterização dos criadouros, quanto ao caráter temporário ou permanente, conforme a terminologia de Maltchik et al. (2004).

Parte dos síntipos das espécies $S$. (T.) chrostowskii, S. (T.) dita e $S$. (T.) hungerfordi coletados no Estado do Paraná, Brasil, que estavam depositados no PMNH, foi destruída durante a Segunda Grande Guerra, em 1944 (Bachmann 1981). Outros síntipos (não observados), estão depositados no SEMC conforme Hungerford (1948) - que os denomina erradamente de parátipos - e Bachmann (1981). De acordo com o artigo 74.7 do ICZN (1999) e tendo em vista que os síntipos depositados no SEMC não foram examinados, lectótipos não foram designados neste estudo.

Todas as medidas foram tomadas com o auxílio de uma ocular milimetrada, acoplada a um estereoscópio. As medidas foram tomadas de espécimes não danificados e apenas dos indivíduos do sexo masculino porque a identificação de indivíduos do sexo feminino é muito difícil, exceto as de $S$. (T.) platensis já que as fêmeas mostraram-se mais fáceis de identificar. As medidas tomadas estão indicadas nas Figs. 113. Para as medidas de largura e comprimento do metaxifo e da pilosidade hidrófoba dos fêmures posteriores os espécimes foram secos. As fotografias usadas foram obtidas a partir de câmara fotográfica digital, acoplada a um estereoscópio. Foi feito o contorno do abdome dos espécimes sobre as fotografias a fim de tornar mais claro o formato de algumas estruturas (e.g., o lóbulo do sétimo segmento abdominal). Quando necessário, as imagens de peças tridimensionais com difíceis e diferentes focagens foram sobrepostas a fim de se obter uma imagem única, a partir do programa CombineZP (Hadley, 2010). Foi usado álcool gel para imobilizar as peças anatômicas e obtenção de boas fotografias, com as estruturas foram totalmente imersas no líquido.

As terminologias de Hungerford (1948) e Bachmann (1981) foram empregadas nas descrições das características da cabeça, tórax e abdome. A identificação dos espécimes baseou-se também nesses trabalhos. A chave dicotômica para as espécies registradas foi baseada em todos os espécimes do sexo masculino estudados e modificada também a partir de Hungerford (1948) e Bachmann (1981). Não foi possível a observação de estruturas do abdome em algumas espécies porque os exemplares estudados apresentaram essa região danificada. Assim, a descrição foi complementada por informações disponíveis em Bachmann (1981), representadas neste estudo entre colchetes.

\section{RESULTADOS}

Nesta seção, são apresentadas as redescrições e ilustrações das sete espécies de Sigara ocorrentes no Estado: $S$. (T.) chrostowskii, S. (T.) dita, S. (T.) denseconscripta, $S$. (T.) hungerfordi, S. (T.) platensis, $S$. (T.) schadei, S. (T.) townsendi. Uma nova espécie é descrita e ilustrada. Notas taxonômicas sobre as espécies são fornecidas com base nas observações realizadas. As espécies $S$. (T.) dita, $S$. (T.) hungerfordi, $S$. (T.) schadei e $S$. (T.) townsendi, foram registradas pela primeira vez no Estado. Houve um incremento do número de espécies ocorrentes no Brasil, sendo $S$. (T.) schadei registrada pela primeira vez no país.

$\mathrm{Na}$ chave de identificação das espécies, muitas espécies só puderam ser distinguidas por combinações de características. Além disso, a chave proposta é destinada, primariamente, para espécimes do sexo masculino; ao identificar-se fêmeas as dificuldades encontradas na identificação dessas espécies são maiores.

\section{Sigara Fabricius, 1775}

Sigara Fabricius, 1775: 691, espécie-tipo: Notonecta striata Linnaeus, 1758 (non Leach), por monotipia.

Basileocorixa Kirkaldy, 1898: 253, espécie-tipo: Notonecta striata Linnaeus, 1758, por designação original - sinonimizado por China (1943).

Pode ser distinguido dos demais gêneros de Corixidae por apresentarem fêmures posteriores com pilosidade hidrófoba cobrindo ao menos o terço basal de sua face ântero-ventral (Fig. 8). Os espécimes do sexo masculino distinguem-se facilmente pela (1) pala com uma fileira de espinhos evidente, (2) o estrigilo posicionado à direita em vista dorsal, (3) uma assimetria abdominal para a direita, em vista ventral (e.g., Figs. 16, 23).

Nota. - As espécies de Sigara com registro no Rio Grande do Sul apresentam como características diagnósticas a fóvea convexa nas fêmeas e ligeiramente côncava nos machos, assim como a área estridulatória dos fêmures anteriores bem desenvolvida em vista ventral (e.g., Fig. 13). Com base nessas características, Hutchinson (1940) definiu o subgênero Tropocorixa Hutchinson, o qual foi formalizado por Hungerford (1948) e adotado neste estudo.

\section{Sigara (Tropocorixa) bachmanni Bernardo \& Ribeiro, sp. nov.} (Figs. 14-17, 57)

Material-tipo examinado.- Holótipo: Brasil. Rio Grande do Sul - Município de São Francisco de Paula [50¹0’20,9”, W/29²1'16,6”S], em ambientes intermitentes, 04.V.2002, (L. Maltchik \& C. Stenert): $1 \mathrm{~m}$ (UNISINOS); parátipos: $1 \mathrm{~m}$ (UNISINOS); $3 \mathrm{~m}$ (LEBIP).

Descrição do holótipo. Biometria. - Comprimento total do corpo: 5,2 mm; largura máxima do corpo: $2,5 \mathrm{~mm}$.

Coloração geral do corpo castanho-escura. Disco pronotal com seis faixas transversais ligeiramente regulares enegrecidas (Fig. 14). 

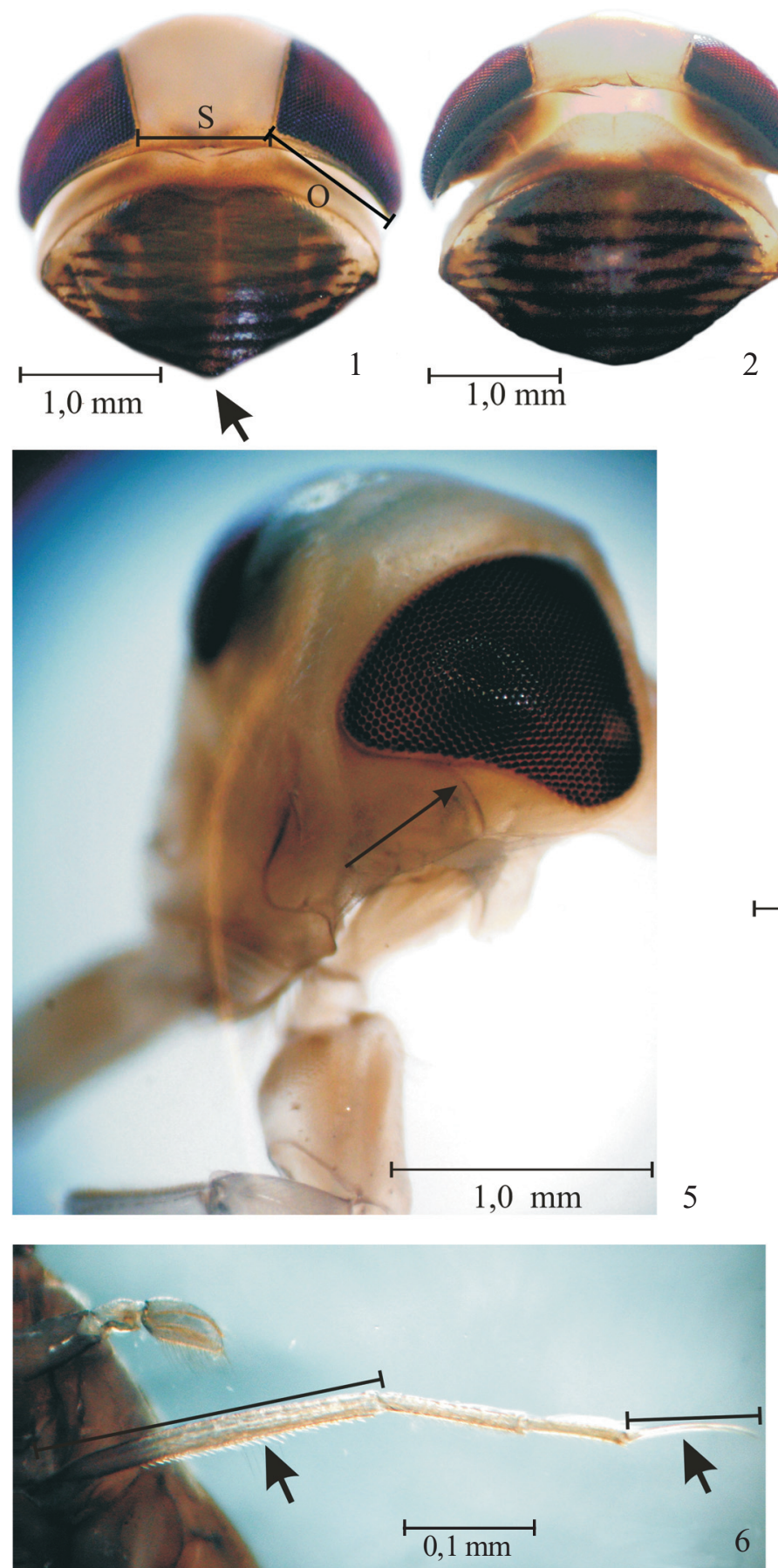

V

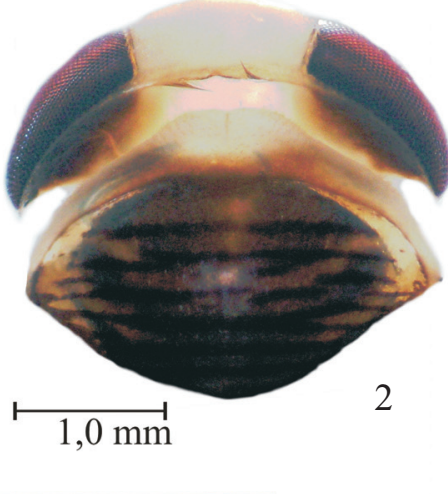

2
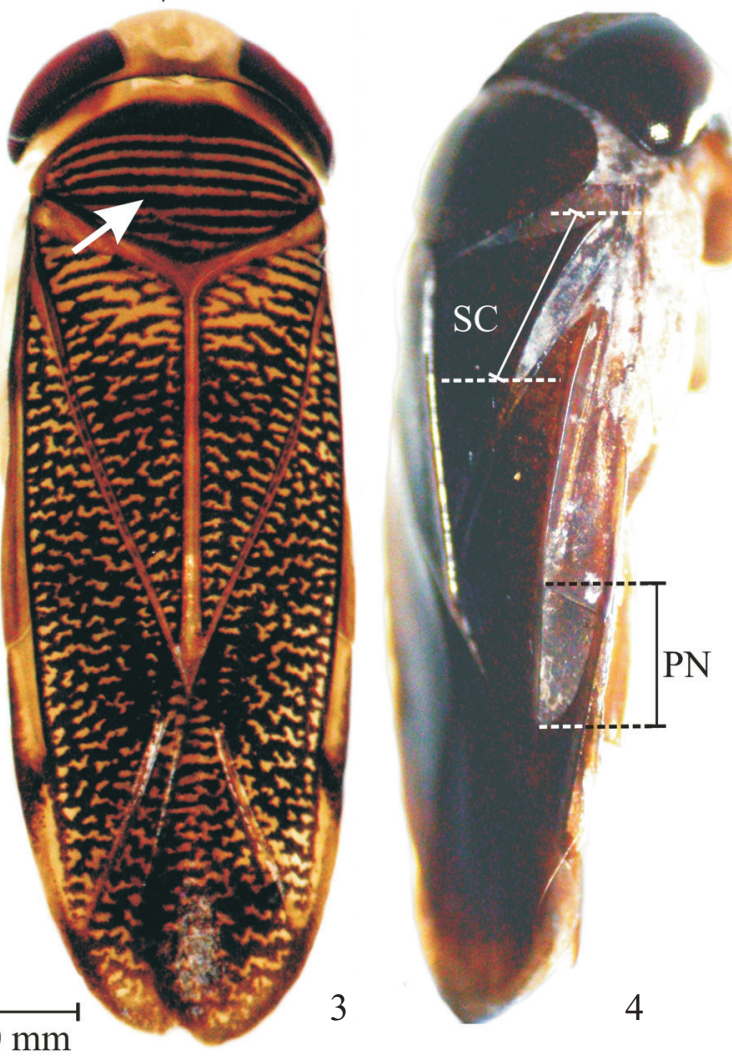

4

Figs. 1-7. Estruturas usadas na obtenção de características morfológicas e métricas de importância na taxonomia das espécies de Sigara Fabricius. 1, Cabeça e pronoto (vista dorsal): seta indicando pronoto com inflexão aguda em sua borda posterior; 2, Pronoto com inflexão arredondada pouco acentuada na sua borda posterior; 3, Corpo (vista dorsal): seta indicando as faixas longitudinais sobre o disco pronotal; 4, Corpo (vista lateral); 5, Cabeça (vista látero-ventral): seta indicando a condição de gena larga; 6, Perna mediana: setas indicando medida de comprimento do fêmur e da garra tarsal; 7, Cabeça de um indivíduo do sexo masculino (vista ventral) indicando a condição plana ou ligeiramente côncava da fóvea: seta indicando gena estreita, quase invisível. Abreviaturas usadas: F, fóvea dos espécimes do sexo masculino em condição larga atingindo a borda pôstero-ventral dos olhos; O, largura da parte posterior do olho; PN, comprimento da pilosidade pós-nodal; S, largura do sintilipso; SC, medida da pilosidade da sutura claval; V, vértice.

Cabeça, tórax e abdome. - Vértice pouco proeminente, não se sobressaindo em relação à borda anterior dos olhos, em vista dorsal (Fig. 14); comprimento do sintilipso menor do que 0,9 vezes a largura da borda posterior de um olho, em vista dorsal; fóvea facial ligeiramente côncava, com pouca pilosidade, não alcançando a borda lateral dos olhos, em vista ventral; gena estreita. Disco pronotal com a borda posterior arredondada, em vista dorsal (Fig. 14); comprimento da pilosidade da área pósnodal igual ao da área da sutura claval; metaxifo mais largo do que comprido; fêmur das pernas anteriores com a área 

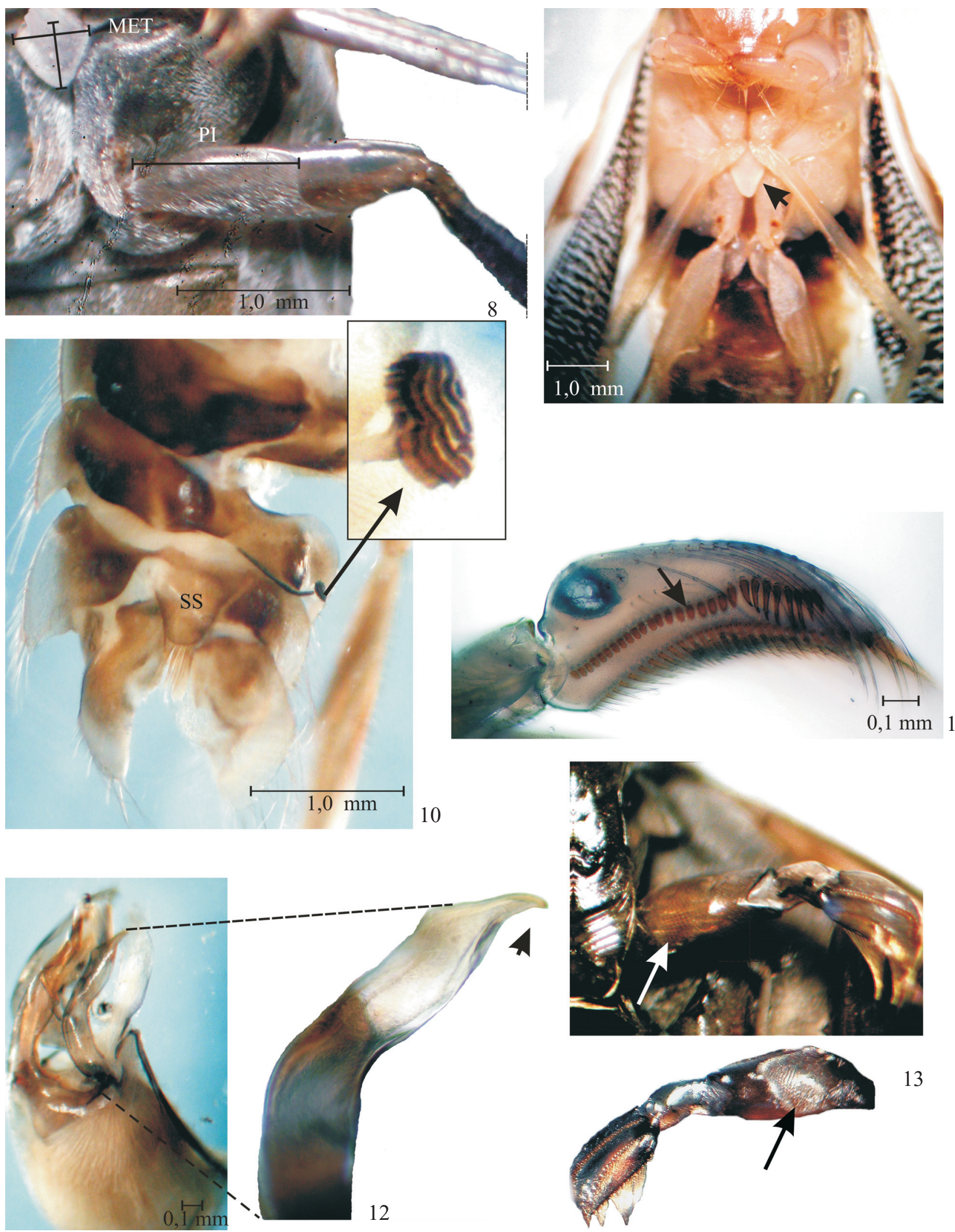

Figs. 8-13. Estruturas usadas na obtenção de características morfológicas e métricas de importância na taxonomia das espécies de Sigara Fabricius. 8, Meso- e metatórax (vista ventral), metaxifo mais largo do que comprido; 9, Meso- e metatórax (vista ventral), metaxifo mais estreito do que comprido; 10, Abdome (vista dorsal): seta indicando detalhe do estrigilo; 11, Pala de um indivíduo do sexo masculino: seta indicando espinhos da pala; 12, Cápsula genital, detalhes de um parâmero direito: seta indicando prolongamento apical; 13, Perna anterior de um indivíduo do sexo masculino (vista lateral): seta indicando área estridular. Abreviaturas usadas: CME, comprimento do metaxifo; LME, largura do metaxifo; PI, comprimento da pilosidade hidrófoba dos fêmures posteriores; SS, lóbulo do sétimo segmento abdominal. 


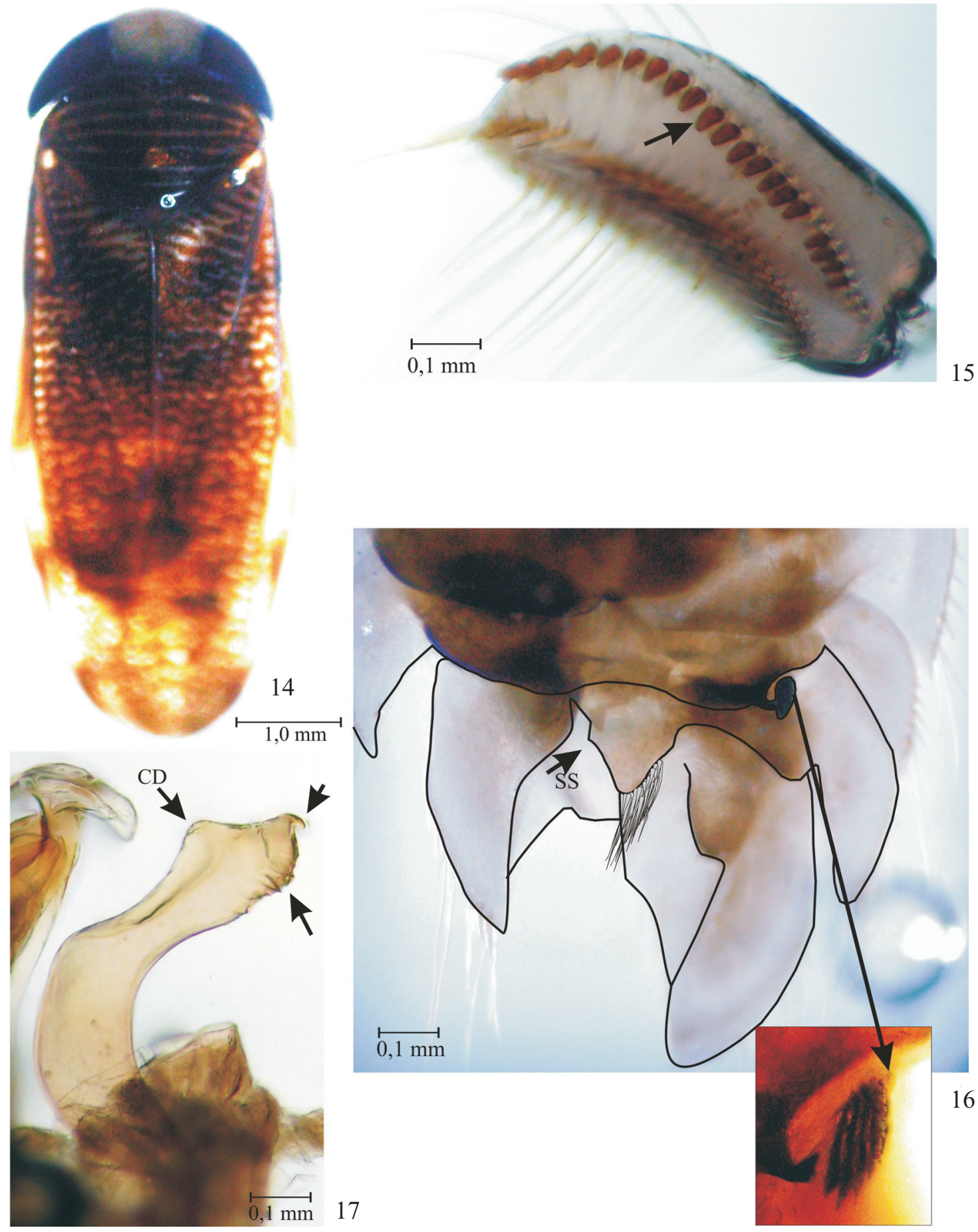

Figs. 14-17. Sigara (Tropocorixa) bachmanni Bernardo \& Ribeiro, sp. nov. 14, Corpo (vista dorsal), holótipo; 15, Pala de um indivíduo do sexo masculino: seta indicando os espinhos da pala; 16, Abdome de um indivíduo do sexo masculino (vista dorsal): seta indicando o lóbulo do sétimo segmento abdominal e detalhe do estrigilo; 17, Parâmero de um indivíduo do sexo masculino. Abreviaturas usadas: CD, crista dorsal; PAP, prolongamento apical em forma de gancho curto; SEP, serrilhados da região pré-apical; SS, lóbulo do sétimo segmento abdominal.

estridulatória desenvolvida, em vista ventral; pala longa e quadrangular, com 25 espinhos, distribuídos em uma fileira que se encurva ligeiramente em sua porção distal; oito espinhos apicais da pala ligeiramente maiores que os demais (Fig. 15); comprimento das garras tarsais das pernas médias três quintos do comprimento do fêmur; comprimento da pilosidade hidrófoba dos fêmures posteriores aproximadamente dois quintos de seu comprimento total em vista ventral. Estrigilo pequeno, alongado e arredondado, com cinco faixas escuras e regulares (Fig. 16); borda do sexto tergito abdominal sem uma expressão caudal na metade direita; laterotergito direito do sétimo segmento abdominal sem saliência; lóbulo do sétimo segmento abdomi- 
nal largo na base, não angulado em suas bordas laterais, afilandose em direção à borda posterior arredondada,com poucas cerdas compridas dispostas ao longo de sua margem (Fig. 16).

Genitália masculina (Fig. 17). - Região basal do parâmero direito ligeiramente larga, afilando-se em sua porção mediana e alargando-se novamente em seu ápice; sem esporão na região anterior; região preapical serrilhada, sem dentes, não emarginada; região apical com uma pequena crista desenvolvida, em vista lateral.

Descrição dos parátipos. Biometria (machos) - Comprimento total do corpo: 5,2-5,4 mm; largura máxima do corpo: 2,0-2,5 $\mathrm{mm}$.

Como no holótipo, exceto pelas seguintes características:

Disco pronotal com o número de faixas transversais enegrecidas variando de cinco a sete; pala com o número de espinhos variando de 22 a 25; comprimento da pilosidade da área pós-nodal igual ou ligeiramente menor que o da área da sutura claval. Estrigilo com o número de faixas escuras e regulares variando de cinco a seis.

Notas comparativas. - Essa nova espécie enquadra-se no passo 13 da chave de Bachmann (1981: 169), que distingue $S$. (T.) hungerfordi de $S$. (T.) santiagiensis e está em melhor conformidade com $S$. (T.) hungerfordi, pois ambas apresentam a largura do sintilipso menor do que 0,9 vezes a largura da borda posterior de um olho, metaxifo mais largo do que comprido, gena estreita, comprimento das garras tarsais das pernas médias aproximadamente dois quintos do comprimento do fêmur e pilosidade hidrófoba dos fêmures posteriores aproximadamente dois quintos de seu comprimento total em vista ventral. Entretanto, difere de $S$. (T.) hungerfordi pelo aspecto do laterotergito direito, que não apresenta uma saliência bem marcada (Figs. 16,39 ), e pelo formato do lóbulo do sétimo segmento que apresenta um prolongamento acentuado na região proximal, tornando a base dessa estrutura muito mais larga do que seu ápice (Fig. 16). A nova espécie pode ser distinguida ainda pelo formato do parâmero direito dos espécimes do sexo masculino, pela presença de um ápice curto, em forma de gancho, uma região preapical saliente, nunca emarginada, com serrilhados, e uma pequena crista dorsal desenvolvida (Fig. 17).

Essa nova espécie é ainda similar à $S$. (T.) dita, pois compartilham as seguintes características: (1) largura do sintilipso menor do que a largura da borda posterior de um olho; (2) metaxifo mais largo do que comprido; e (3) genas estreitas.

\section{Sigara (Tropocorixa) chrostowskii Jaczewski, 1927}

(Figs. 18-24, 55, 57)

Sigara (Sigara) chrostowskii Jaczewski, 1927: 42.

Arctocorixa chrostowskii var. brachypala: Hungerford (1928): 177.

Sigara chrostowskii: Jaczewski (1931): 147.

Sigara (Tropocorixa) brachypala Hungerford (1948): 765 [sinonimizada por Bachmann (1981)].

Sigara (Tropocorixa) chrostowskii: Hungerford (1948): 765.

Informações sobre os tipos. - Parte dos síntipos foi destruída durante a Segunda Grande Guerra, em 1944 (Bachmann 1981). Sem lectótipo designado.
Material examinado. - Brasil. Rio Grande do Sul - Encruzilhada do Sul [52 $31^{\prime} 48,2$ ' W/30 $53^{\prime}$ '08,4”S], em ambiente permanente, 25.VII.2002, (L. Maltchik \& C. Stenert): 2 m (UNISINOS). Mostardas [50³0’32,2”W/ 30³7'23,8”S] ["lav seca”], em ambiente permanente, III.2006, (C. Stenert): 2 m (UNISINOS); ["canal úmido G”], 15.III.2002, (L. Maltchik \& C. Stenert): 1

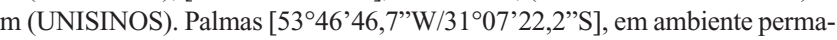
nente, 21.IV.2002, (L. Maltchik \& C. Stenert); 3 m (UNISINOS). Palmares do Sul [50²9’42,8’W/30¹4'53,8’S], 15.III.2002, (L. Maltchik \& C. Stenert): 1 m (UNISINOS). Rio Grande [52 $18^{\prime} 23,1^{\prime \prime} \mathrm{W} / 31^{\circ} 57^{\prime} 47,5^{\prime \prime} \mathrm{S}$ ], em ambiente permanente, 06.IV.2002, (L. Maltchik \& C. Stenert): 2 m (UNISINOS). Rosá-

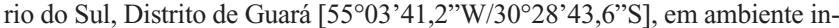
termitente, 19.VII.2002, (L. Maltchik \& C. Stenert): $1 \mathrm{~m}$ (UNISINOS). Santa Vitória do Palmar [52 $40 ' 19,8^{\prime \prime} \mathrm{W} / 32^{\circ} 47^{\prime} 40,4$ 'S], em ambiente permanente, 06.IV.2002, (L. Maltchik \& C. Stenert): 1 m (UNISINOS). Santiago, Distrito de Ernesto Alves [54⒋ $\mathrm{W} / 29^{\circ} 22^{\prime} \mathrm{S}$ ], em criadouro com macrófitas na beira da estrada, ambiente intermitente, 25.X.2009, (F. Stefanello, C. P. Burchard, J. R. I. Ribeiro, L. P. Bernardo): 1 m (LEBIP 56). São Caetano [51 $51^{\prime}$ '06,7'W/ 31'52'36,7'S], em ambiente permanente, 16.III.2002, (L. Maltchik \& C. Stenert): 4 m (UNISINOS). São Francisco [5455’22,7'W/2941'38,8'S], em ambiente intermitente, 12.X.2002, (L. Maltchik \& C. Stenert): $4 \mathrm{~m}$ (UNISINOS). São Gabriel [54’21'45,55'W/30²0'1,81'’S], em criadouro com macrófitas na beira da estrada, 25.XI.2009, (L. P. Bernardo): $1 \mathrm{~m}$ (LEBIP 63). São Sepé [53³7’07,0”W/3007’07,2”S], em margem de criadouro, 25.VII.2002, (L. Maltchik \& C. Stenert): $1 \mathrm{~m}$ (UNISINOS).

Redescrição baseada em espécimes do sexo masculino. Biometria. - Comprimento total do corpo: 5,1-5,8 mm; largura máxima do corpo: 1,8-2,3 mm.

Coloração geral do corpo variando de castanho-clara a castanho-escura. Disco pronotal com seis faixas transversais regulares enegrecidas (Figs. 18-20); região ventral do tórax de muitos indivíduos com manchas castanho-escuras.

Cabeça, tórax e abdome. - Vértice pouco proeminente, não se sobressaindo em relação à borda anterior dos olhos, em vista dorsal (Figs. 18-20); comprimento do sintilipso menor do que 0,9 vezes a largura da borda posterior de um olho, em vista dorsal; fóvea facial larga e ligeiramente côncava, com pouca pilosidade, alcançando a borda lateral dos olhos, em vista ventral; gena estreita. Disco pronotal com a borda posterior variando de arredondada à ligeiramente pronunciada, podendo apresentar uma inflexão, em vista dorsal (Figs. 18-20); comprimento da pilosidade da área pós-nodal aproximadamente igual ao da área da sutura claval; metaxifo mais largo do que comprido; fêmur das pernas anteriores com a área estridulatória desenvolvida, em vista ventral; pala longa podendo ser subtriangular ou quadrangular (e.g., 20-21), com o número de espinhos variando entre 23 e 29, distribuídos em uma fileira que se encurva ligeiramente em sua porção distal; cinco espinhos apicais da pala ligeiramente maiores que os demais (Figs. 21-22); comprimento das garras tarsais das pernas médias variando de 0,4 a 0,5 vezes o comprimento do fêmur; comprimento da pilosidade hidrófoba dos fêmures posteriores aproximadamente a metade de seu comprimento total em vista ventral. Estrigilo grande e arredondado, com seis bandas escuras e regulares (Fig. 23); borda posterior do sexto tergito abdominal com uma ampla expressão caudal na metade direita, quase atingindo a borda posterior do sétimo segmento (Fig. 23); laterotergito direito do sétimo segmento abdominal apresentando uma saliência bem marcada; lóbulo do sétimo segmento abdominal largo na base, com um ângulo 

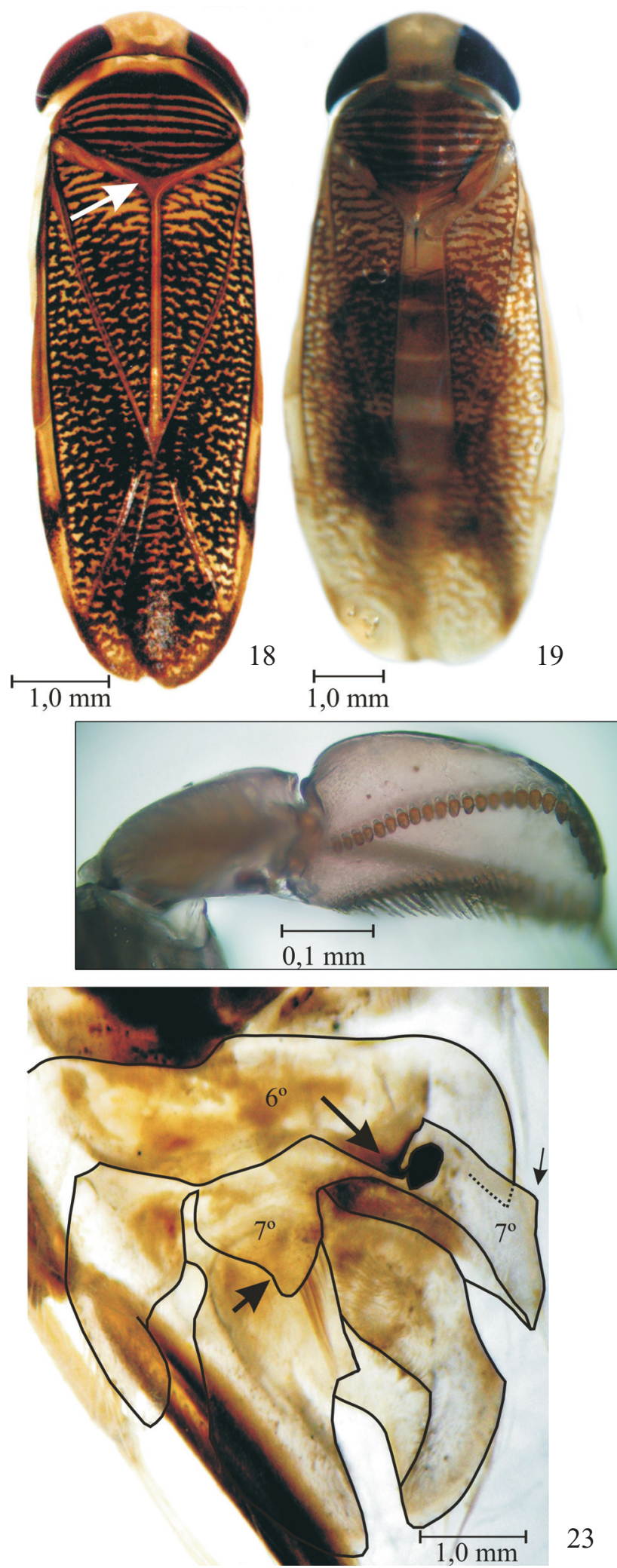
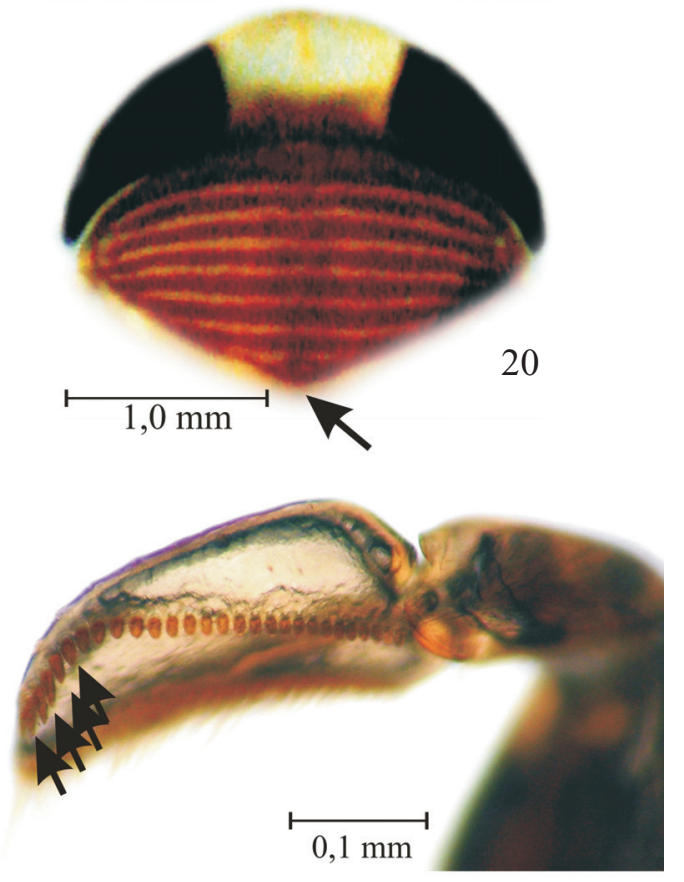

21
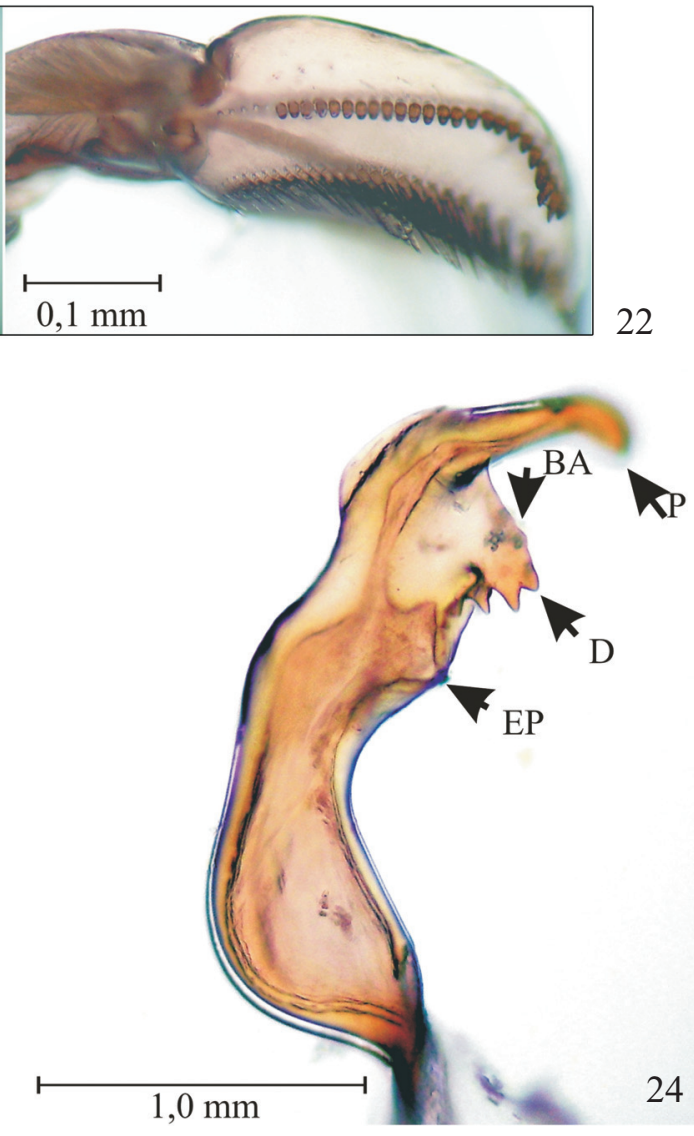

Figs. 18-24. Sigara (Tropocorixa) chrostowskii Jaczewski, 1927. 18, Corpo (vista dorsal) de um espécime com coloração castanho-clara: seta indicando a borda posterior do disco pronotal arredondada, com uma inflexão pouco acentuada; 19, Corpo (vista dorsal) de um espécime com coloração castanhoescura; 20, Cabeça e disco pronotal (vista dorsal): seta indicando borda posterior do disco pronotal com uma inflexão; 21-22, Pala de dois indivíduos do sexo masculino (vista lateral): variação no tamanho, formato e no número de seus espinhos: seta indicando espinhos apicais maiores do que os demais; 23 , Abdome de um indivíduo do sexo masculino (vista dorsal): seta indicando a expressão caudal do sexto segmento abdominal, laterotergito direito do sétimo segmento abdominal com saliência bem marcada e ângulo em seu lóbulo central; 24, Parâmero de um espécime do Município de Mostardas. Abreviaturas usadas: BA, região basal do prolongamento apical; D, dentes; EP, esporão proximal; P, prolongamento apical. 
pouco evidente na borda lateral esquerda, afilando-se em direção à borda posterior arredondada com algumas cerdas compridas e curtas dispostas ao longo de sua margem (Fig. 23).

Genitália masculina (Fig. 24). - Região anterior do parâmero direito larga, com um esporão ligeiramente desenvolvido, em vista lateral; número de dentes da região preapical do parâmero direito variando de três a sete; região apical com um prolongamento em forma de gancho longo.

Distribuição geográfica no Brasil. - Minas Gerais, São Paulo, Paraná, Santa Catarina, Rio Grande do Sul (Jaczewski 1927; Hungerford 1948; Kleerekoper 1955; Nieser \& Melo 1997). Essa espécie foi registrada no Estado do Rio Grande do Sul nos Municípios de Encruzilhada do Sul, Guará, Mostardas, Palmas, Palmares do Sul, Rio Grande, Santa Vitória do Palmar, Santiago (Distrito de Ernesto Alves), São Caetano, São Francisco, São Gabriel, São Sepé (Fig. 57).

Variações morfológicas (Fig. 55). - Alguns espécimes apresentam a pala subtriangular, com a base mais larga do que o ápice. Variações no número de espinhos e formato das palas (Figs. 21-22), no número e disposição dos dentes da região preapical do parâmero direito e no grau de desenvolvimento do exporão proximal foram registradas em vários espécimes de $S$. (T.) chrostowskii coligidos (Tabela I).
Notas comparativas. - Essa espécie é similar à $S$. (T.) townsendi, como observado por Bachmann (1981). As seguintes características são compartilhadas entre elas: largura do sintilipso menor do que a largura da borda posterior de um olho, em vista dorsal; metaxifo mais largo do que comprido; genas estreitas; e parâmero direito do macho com o ápice alongado e estreito, em forma de gancho (Fig. 24) Entretanto, segundo Hungerford (1948), S. (T.) chrostowskii difere-se de $S$. (T.) townsendi pela coloração geral do corpo menos escura, pelo maior porte de seus representantes e pela ausência de uma conspícua área serrilhada na região preapical do parâmero direito dos machos (Figs. 52, 54). Conforme Bachmann (1981), o número de dentes na porção preapical do parâmero direito dos espécimes do sexo masculino de $S$. (T.) chrostowskii varia de três a sete. Este é o primeiro autor, inclusive, a mencionar que $S$. (T.) chrostowskii é definida como tendo de três a sete dentes no parâmero. Neste estudo, houve uma tentativa de se relacionar as variações no número de dentes dessa região do parâmero de espécimes de diferentes localidades do Estado com o número de espinhos e formato da pala dos machos, a relação entre o comprimento da garra tarsal e o comprimento do fêmur das pernas medianas, o grau de inflexão da borda posterior do disco pronotal e o

Tabela I. Sumário das variações observadas em diferentes estruturas morfológicas estudadas nas espécies Sigara (Tropocorixa) chrostowskii e $S$. (T.) townsendi ocorrentes em diferentes localidades do Estado do Rio Grande do Sul, Brasil.

\begin{tabular}{|c|c|c|c|c|c|c|c|c|}
\hline \multirow{2}{*}{ Espécie } & \multirow{2}{*}{ Localidade } & \multicolumn{3}{|c|}{ Parâmero } & \multirow{2}{*}{ Pronoto } & \multirow{2}{*}{$\mathrm{CGT} / \mathrm{CFE}$} & \multicolumn{2}{|r|}{ Pala } \\
\hline & & Dentes & Disposição dos dentes & Esporão proximal & & & Espinhos & Formato \\
\hline \multirow[t]{8}{*}{ S. (T.) chrostowskii } & Guará & 4 & $\begin{array}{l}\text { primeiro dente distante da base } \\
\text { do prolongamento apical }\end{array}$ & não tem & com inflexão & 0,40 & 31 & $\begin{array}{l}\text { um pouco mais larga } \\
\text { na região proximal }\end{array}$ \\
\hline & São Sepé & 5 & $\begin{array}{l}\text { primeiro dente distante da base } \\
\text { do prolongamento apical }\end{array}$ & $\begin{array}{l}\text { ligeiramente evidente, sem } \\
\text { alcançar a altura do maior } \\
\text { dente }\end{array}$ & com inflexão & - & 25 & $\begin{array}{l}\text { um pouco mais larga } \\
\text { na região proximal }\end{array}$ \\
\hline & Rio Grande & 5 & $\begin{array}{l}\text { primeiro dente distante da base } \\
\text { do prolongamento apical }\end{array}$ & $\begin{array}{l}\text { ligeiramente evidente, sem } \\
\text { alcançar a altura do maior } \\
\text { dente }\end{array}$ & com inflexão & 0,46 & - & não foi observado \\
\hline & Palmas & 5 & $\begin{array}{l}\text { primeiro dente próximo da base } \\
\text { do prolongamento apical }\end{array}$ & $\begin{array}{l}\text { muito evidente, alcançando a } \\
\text { altura do maior dente }\end{array}$ & arredondado & 0,50 & 26 & $\begin{array}{l}\text { de mesma largura em } \\
\text { toda a extensão }\end{array}$ \\
\hline & Mostardas (a)* & 5 & $\begin{array}{l}\text { primeiro dente distante da base } \\
\text { do prolongamento apical }\end{array}$ & $\begin{array}{l}\text { ligeiramente evidente, sem } \\
\text { alcançar a altura do maior } \\
\text { dente }\end{array}$ & com inflexão & 0,42 & 28 & $\begin{array}{l}\text { um pouco mais larga } \\
\text { na região proximal }\end{array}$ \\
\hline & Mostardas (b)* & 5 & $\begin{array}{l}\text { primeiro dente distante da base } \\
\text { do prolongamento apical }\end{array}$ & $\begin{array}{l}\text { ligeiramente evidente, sem } \\
\text { alcançar a altura do maior } \\
\text { dente }\end{array}$ & com inflexão & 0,46 & 27 & $\begin{array}{l}\text { um pouco mais larga } \\
\text { na região proximal }\end{array}$ \\
\hline & Mostardas (c)* & 5 & $\begin{array}{l}\text { primeiro dente distante da base } \\
\text { do prolongamento apical }\end{array}$ & não tem & com inflexão & 0,46 & 24 & $\begin{array}{l}\text { um pouco mais larga } \\
\text { na região proximal }\end{array}$ \\
\hline & São Francisco & 7 & $\begin{array}{l}\text { primeiro dente próximo da base } \\
\text { do prolongamento apical }\end{array}$ & $\begin{array}{l}\text { muito evidente, alcançando a } \\
\text { altura do maior dente }\end{array}$ & com inflexão & 0,43 & 28 & $\begin{array}{l}\text { um pouco mais larga } \\
\text { na região proximal }\end{array}$ \\
\hline \multirow[t]{4}{*}{ S. (T.) townsendi } & Mostardas (a)* & 8 & $\begin{array}{l}\text { primeiro dente próximo da base } \\
\text { do prolongamento apical }\end{array}$ & $\begin{array}{l}\text { ligeiramente evidente, mas } \\
\text { sem alcançar a altura do } \\
\text { maior dente }\end{array}$ & com inflexão & 0,46 & 27 & $\begin{array}{l}\text { um pouco mais larga } \\
\text { na região proximal }\end{array}$ \\
\hline & Mostardas (b)* & 8 & $\begin{array}{l}\text { primeiro dente distante da base } \\
\text { do prolongamento apical e área } \\
\text { com ondulação }\end{array}$ & não tem & com inflexão & 0,47 & 27 & $\begin{array}{l}\text { um pouco mais larga } \\
\text { na região proximal }\end{array}$ \\
\hline & São Caetano & 8 & $\begin{array}{l}\text { primeiro dente distante da base } \\
\text { do prolongamento apical e área } \\
\text { com ondulação }\end{array}$ & $\begin{array}{l}\text { ligeiramente evidente, mas } \\
\text { sem alcançar a altura do } \\
\text { maior dente }\end{array}$ & com inflexão & 0,40 & 29 & $\begin{array}{l}\text { um pouco mais larga } \\
\text { na região proximal }\end{array}$ \\
\hline & Palmas & 12 & $\begin{array}{l}\text { primeiro dente próximo da base } \\
\text { do prolongamento apical }\end{array}$ & $\begin{array}{l}\text { muito evidente, alcançando a } \\
\text { altura do maior dente }\end{array}$ & com inflexão & 0,47 & 28 & $\begin{array}{l}\text { de mesma largura em } \\
\text { toda a extensão }\end{array}$ \\
\hline
\end{tabular}

*Variações individuais encontradas no Município de Mostardas.

**Abreviaturas usadas: CGT, comprimento das garras tarsais das pernas médias; CFE, comprimento do fêmur. 
número de faixas enegrecidas do estrigilo (Tabela I) (Fig. 55). Como parece não haver de fato relação entre esses elementos, todos os espécimes com número de dentes entre três e sete foram tratados, neste estudo, como representantes de S. (T.) chrostowskii.

\section{Sigara (Tropocorixa) denseconscripta (Breddin, 1897)}

(Figs. 25-28, 57)

Corixa denseconscripta Breddin, 1897 apud Hungerford (1948): 16. Arctocorisa denseconscripta: Kirkaldy \& Torre-Bueno (1909): 195. Sigara (Sigara) denseconscripta: Jaczewski (1927) apud Hungerford (1948): 251.

Sigara denseconscripta: Jaczewski (1931): 145.

Sigara (Tropocorixa) densecosncripta: Hungerford (1948): 765.

Informações sobre o tipo. - Breddin descreveu essa espécie com base em um holótipo do sexo feminino coligido em Buenos Aires, Argentina e depositado no ZMH. Entretanto, Hungerford (1948) menciona não ter encontrado o tipo em 1928.

Material examinado. - São Gabriel [54²1'45,55”W/30²0’1,81”S], em revoada em lâmpadas fluorescentes, 25.XI.2009, (L. P. Bernardo): 1 m (LEBIP 21).

Redescrição baseada em apenas um espécime do sexo masculino

Biometria. - Comprimento total do corpo: 7,0 mm; largura máxima do corpo: 2,4 $\mathrm{mm}$.

Coloração geral do corpo castanho-clara. Disco pronotal com seis faixas transversais irregulares enegrecidas (Fig. 26); região ventral do tórax sem manchas castanho-escuras. Região dorsal e ventral do abdome com manchas castanho-escuras.

Cabeça, tórax e abdome. - Vértice pouco proeminente, não se sobressaindo em relação à borda anterior dos olhos, em vista dorsal (Fig. 26); comprimento do sintilipso maior do que 0,9 vezes a largura da borda posterior de um olho, em vista dorsal; fóvea facial larga e ligeiramente côncava, com pouca pilosidade, alcançando a borda lateral dos olhos, em vista ventral; gena estreita. Disco pronotal com a borda posterior arredondada, em vista dorsal (Fig. 26); metaxifo mais estreito que comprido (Fig. 25); fêmur das pernas anteriores com área estridulatória desenvolvida, em vista ventral; pala dos espécimes do sexo masculino longa e subtriangular, com 28 espinhos, distribuídos em uma fileira que se encurva muito em sua porção distal; oito espinhos apicais da pala muito maiores que os demais (Fig. 27); comprimento das garras tarsais das pernas médias aproximadamente metade do comprimento do fêmur; comprimento da pilosidade hidrófoba dos fêmures posteriores aproximadamente a metade de seu comprimento total em vista ventral; comprimento da pilosidade da área pós-nodal aproximadamente igual a da área da sutura claval. [Estrigilo pequeno e elíptico, com o número de faixas variando de três a cinco faixas escuras e regulares; borda posterior do sexto tergito abdominal com uma ampla expressão caudal em sua metade direita, atingindo a borda posterior do sétimo segmento; laterotergito direi- to do sétimo segmento abdominal com uma saliência; lóbulo do sétimo segmento abdominal pequeno, arredondado, com poucas cerdas compridas dispostas ao longo de sua margem].

Genitália masculina (Fig. 28). - Região basal do parâmero direito largo, afilando-se e encurvando-se em sua porção mediana, sem esporão na região anterior; porção apical aguda, com uma forma aproximada de "C", em vista lateral.

Distribuição geográfica no Brasil. - Minas Gerais e Rio Grande do Sul (Moreira et al., 2011). Essa espécie foi registrada pela primeira vez no Estado do Rio Grande do Sul, no Município de São Gabriel (Fig. 57).

Notas comparativas. - Essa espécie é similar à $S$. (T.) schadei. As seguintes características são compartilhadas entre eles: largura do sintilipso maior do que 0,9 vezes o comprimento de um olho; e o metaxifo mais estreito do que comprido. Entretanto, são diferenciadas pelo aspecto da borda posterior do disco pronotal, o qual é arredondado em $S$. (T.) denseconscripta (Fig. 26) e inflexionado em $S$. (T.) schadei (Fig. 46). A espécie $S$. (T.) denseconscripta é diferenciada das demais deste estudo pelo formato de seu parâmero direito, que apresenta a porção apical aguda, com uma forma aproximada de "C", em vista lateral (Fig. 28). Neste estudo, o único espécime examinado apresentou o metaxifo mais estreito do que comprido, o que contraria a descrição de Bachmann (1981). Em sua chave de identificação, Bachmann indica, em outra espécie, uma situação parecida com a que foi observada aqui: a espécie $S$. (T.) hungerfordi aparentemente tem uma variação no formato do metaxifo, com representantes apresentando-no mais estreito que comprido e mais largo que comprido. Entretanto, isso não foi mencionado na descrição dessa espécie pelo autor. Hungerford (1948) observou um número maior de espinhos na pala dos representantes do sexo masculino dessa espécie. Enquanto, neste estudo, foram observados 28 espinhos (oito deles maiores que os demais) (Fig. 27), o autor observou 30 espinhos (10 a 12 deles maiores que os demais).

\section{Sigara (Tropocorixa) dita Jaczewski, 1927}

$$
\text { (Figs. 29-35, 57) }
$$

Sigara (Sigara) dita Jaczewski, 1927: 46.

Arctocorixa dita: Hungerford (1928): 182., pr. 7 (figs. 1-2).

Sigara dita: Jaczewski (1931): 147.

Sigara (Tropocorixa) dita: Hungerford (1948): 765.

Informações sobre os tipos. - Parte dos síntipos foi destruída durante a Segunda Grande Guerra, em 1944 (Bachmann 1981). Sem lectótipo designado.

Material examinado. - Manoel Viana [55¹5’23,1”W/29²9’07,2”S], em ambiente permanente, 12.X.2002, (L. Maltchik \& C. Stenert): $4 \mathrm{~m}$ (UNISINOS). Rosário do Sul, Distrito de Armada [5508'40,4"W/ 3043'34,7'S], em ambiente intermitente, 19.VII,2002, (L. Maltchik \& C. Stenert): $2 \mathrm{~m}$ (UNISINOS). Santana do Livramento [55 $23^{\prime} 22,7^{\prime \prime} \mathrm{W} /$ 3050'16,9'S], em ambiente intermitente, 19.VII.2002, (L. Maltchik \& C. Stenert): 2 m (UNISINOS). Santiago, Distrito de Ernesto Alves [5444' W/29 $22^{\prime}$ S ], em criadouro com macrófitas na beira da estrada, em ambiente intermitente, 25.X.2009, (F. Stefanello, C. P. Burchard, J. R. I. Ribei- 

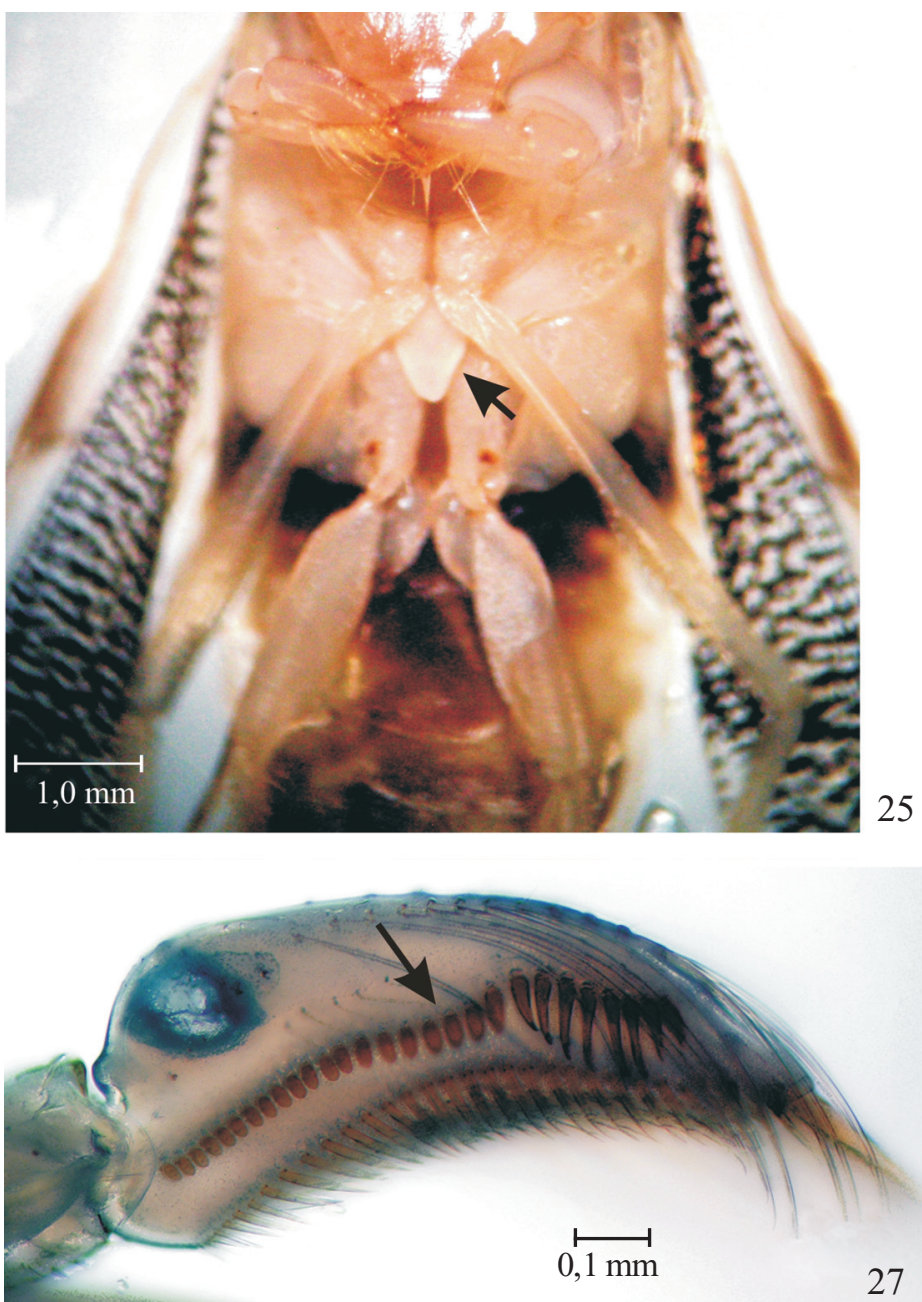

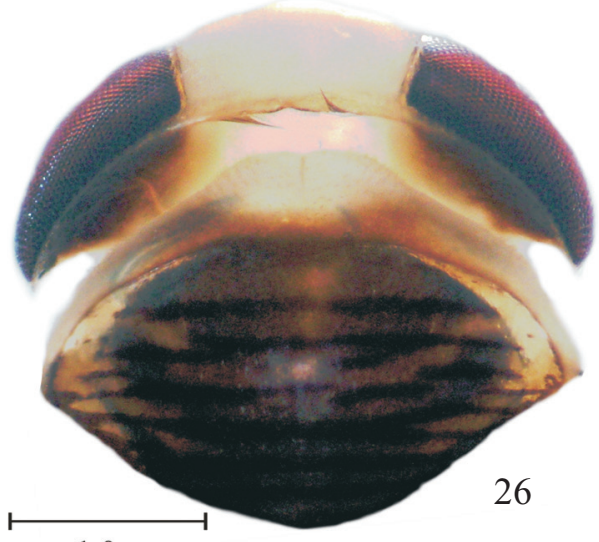

$1,0 \mathrm{~mm}$

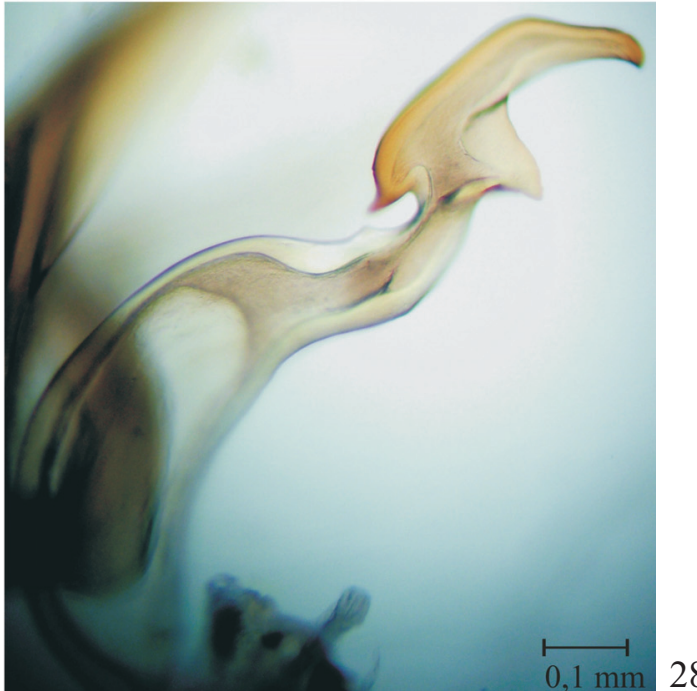

Figs. 25-28. Sigara (Tropocorixa) denseconscripta (Breddin, 1897). 25, Tórax (vista ventral): seta indicando o metaxifo mais estreito que comprido; 26, Cabeça e disco pronotal (vista dorsal); 27, Pala de um indivíduo do sexo masculino: seta indicando a disposição e o formato dos espinhos da pala; 28 , Parâmero direito de um indivíduo do sexo masculino (vista lateral).

ro, L. P. Bernardo): 3 m (LEBIP 114). São Francisco de Paula [50 10 '20,9'W/29²1'16,6”S], em ambiente intermitente, 04.V.2002, (L. Maltchik \& C. Stenert): $1 \mathrm{~m}$ (UNISINOS).

Redescrição baseada em espécimes do sexo masculino e feminino. Biometria. - Comprimento total do corpo: 5,25,4 mm; largura máxima do corpo: 2,0-2.5 mm.

Coloração geral do corpo variando de castanho-clara a castanho-escura. Disco pronotal com seis faixas transversais regulares enegrecidas; região dorsal e ventral do tórax de alguns indivíduos com manchas castanho-escuras. Abdome com mesmo padrão de cores que o tórax.

Cabeça, tórax e abdome. - Vértice dos espécimes do sexo masculino pouco proeminente, não se sobressaindo em relação à borda anterior dos olhos, e não proeminente na fêmea, em vista dorsal (Figs. 29-30); comprimento do sintilipso menor do que 0,9 vezes a largura da borda posterior de um olho, em vista dorsal; fóvea facial larga e ligeiramente côncava, com pouca pilosidade, alcançando a borda lateral dos olhos, em vista ventral; gena estreita. Disco pronotal com a borda posterior arredondada, em vista dorsal (Figs. 29-30); comprimento da pilosidade da área pós-nodal menor do que a da área da sutura claval; metaxifo mais largo do que comprido; fêmur das pernas anteriores com área estridulatória desenvolvida, em vista ventral; pala dos espécimes do sexo masculino longa e ligeiramente quadrangular; pala com 26 espinhos tanto nos machos como nas fêmeas, distribuídos em uma fileira que se encurva ligeiramente em sua porção distal; cinco espinhos apicais da pala ligeiramente maiores que os demais (Fig. 31); comprimento das garras tarsais das pernas médias aproximadamente a metade do comprimento do fêmur; comprimento da pilosidade hidrófoba dos fêmures posteriores aproximadamente a metade de seu comprimento total em vista ventral. Estrigilo pequeno e arredondado, com três faixas escuras e regulares; borda posterior do sexto tergito abdominal sem uma expressão caudal em sua metade direita; laterotergito direito do sétimo segmento abdominal sem saliência; lóbulo do sétimo segmento abdominal largo na base, não angulado em suas bordas laterais, afilando-se ligeiramente em direção à borda posterior arredondada, com muitas cerdas compridas dispostas ao longo de sua margem (Fig. 35). 

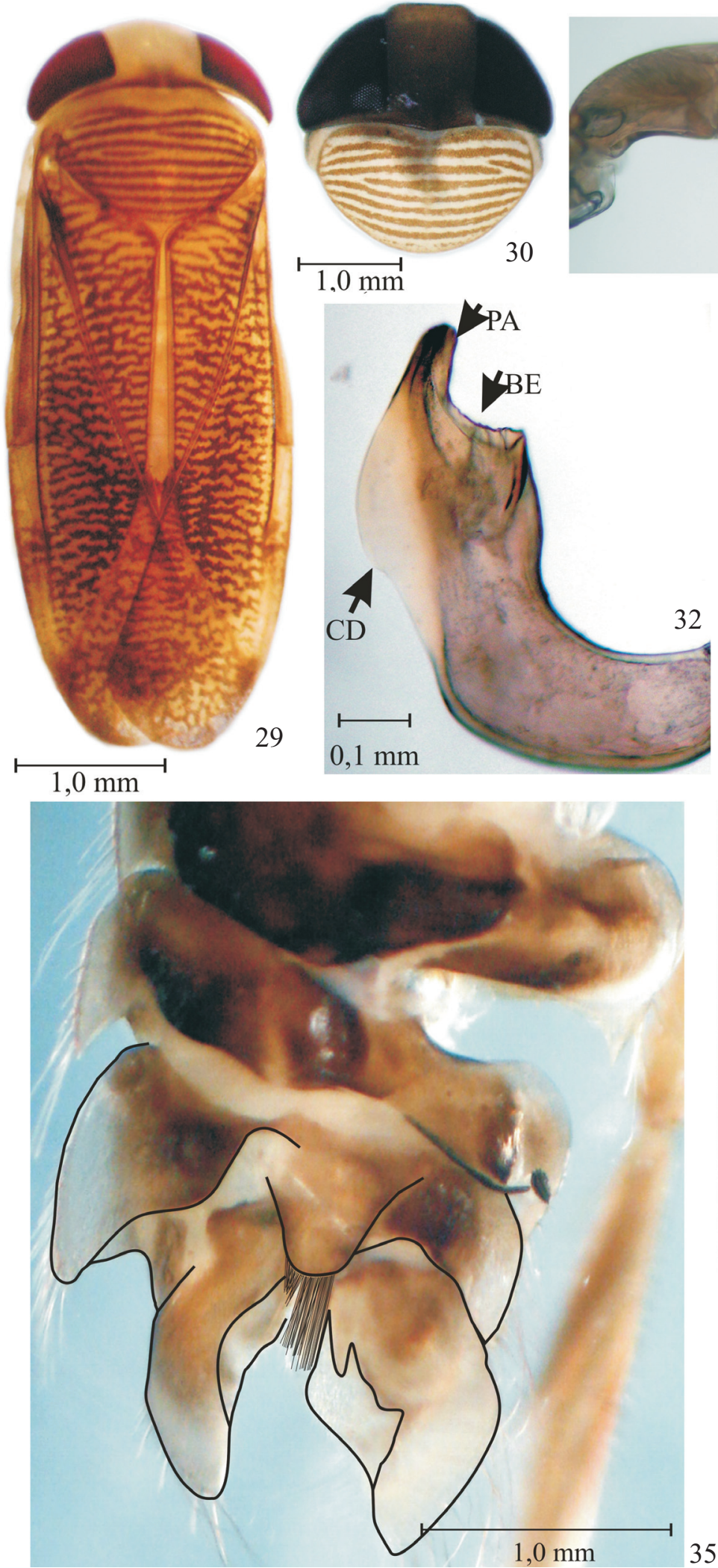
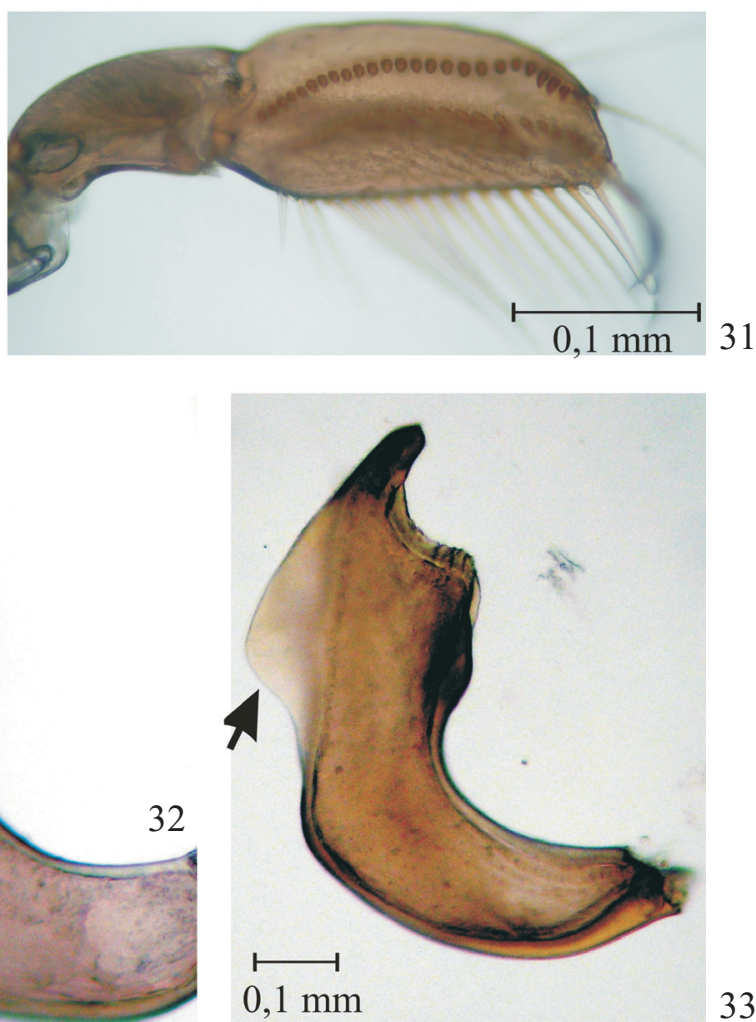

33

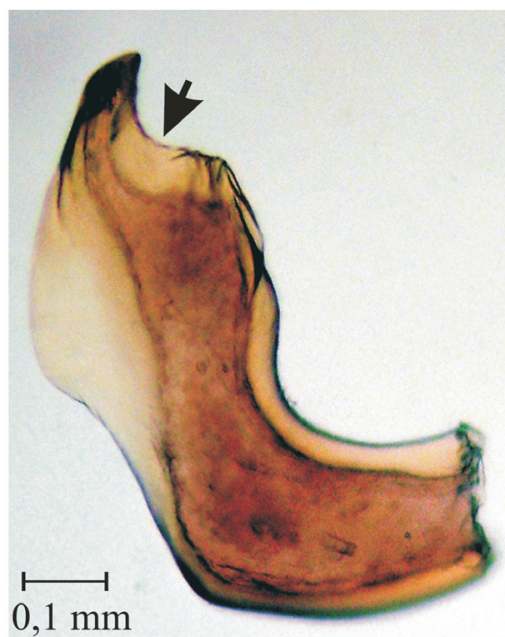

34

Figs. 29-35. Sigara (Tropocorixa) dita Jaczewski, 1927. 29, Corpo de um indivíduo do sexo masculino (vista dorsal); 30, Cabeça e disco pronotal de um indivíduo do sexo feminino (vista dorsal); 31, Pala de um indivíduo do sexo masculino (vista lateral). 32-34, Amplitude de variação observada no parâmero direito dos indivíduos do sexo masculino estudados; 32, Indivíduo do sexo masculino do Município de Santana do Livramento; 33, Indivíduo do sexo masculino do Município de Manoel Viana: seta indicando a crista; 34, Indivíduo do sexo masculino do Município de Santana do Livramento: seta indicando a borda emarginada; 35, Abdome de um indivíduo do sexo masculino. Abreviaturas usadas: BE, borda emarginada; CD, crista dorsal; PA, prolongamento apical. 
Genitália masculina (Figs. 32-34). - Parâmero direito largo, sem esporão na região anterior, em vista lateral; porção mediana e apical com uma estrutura em forma de crista longa, transparente, em vista lateral; região preapical emarginada, com a borda serrilhada; região apical com um prolongamento curto, não em forma de gancho.

Distribuição geográfica no Brasil. - Espírito Santo, São Paulo, Paraná, Santa Catarina (Jaczewski 1927; Hungerford 1948; Moreira et al. 2011). Essa espécie é registrada pela primeira vez no Estado do Rio Grande do Sul, nos seguintes Municípios: Manoel Viana, Rosário do Sul (Distrito de Armada), Santana do Livramento, Santiago (Distrito de Ernesto Alves) e São Francisco de Paula (Fig. 57).

Variações morfológicas (Figs. 32-34). - Foram observadas ligeiras variações em diferentes regiões do parâmero direito dos representantes do sexo masculino dessa espécie, sendo elas listadas a seguir: (1) tamanho reduzido ou acentuado da crista da porção mediana estendendo-se até a região apical; (2) região preapical ligeiramente ou fortemente emarginada; (3) região apical com prolongamento curto, base larga, afilando-se pouco ou muito em direção ao ápice.

Notas comparativas. - Jaczewski (1927) estudou alguns espécimes do sexo masculino de $S$. (T.) dita com o ápice do parâmero direito curvo e liso, bem como curvo e serrilhado. Além disso, destacou que a curvatura do ápice desses parâmeros tem orientação sinistrogira ou dextrogira. Hungerford (1948) descreveu pequenas variações no número de espinhos da pala dos espécimes do sexo masculino e no número de faixas escuras do estrigilo: o número de espinhos da pala variou entre 24 e 30 e o número de faixas escuras do estrigilo, entre três e quatro. Neste estudo, talvez pelo pequeno número de espécimes disponíveis, não foi possível observar tal variação. Essa espécie é similar à $S$. (T.) bachmanni sp. nov. As seguintes características são compartilhadas entre elas: largura do sintilipso menor do que a largura da borda posterior de um olho; metaxifo mais largo do que comprido; e genas estreitas. Entretanto, S. (T.) bachmanni sp. nov difere de $S$. ( $T$.) dita pelo comprimento das garras tarsais das pernas médias 0,4 vezes o comprimento do fêmur, pelo número de faixas escuras no disco pronotal - que varia de seis a sete - e pelo formato do ápice do parâmero direito, mais curto e ligeiramente curvado, com uma área serrilhada evidente (compare Figs. 17 e 32).

\section{Sigara (Tropocorixa) hungerfordi Jaczewski, 1927}

$$
\text { (Figs. 36-39, 58) }
$$

Sigara (Sigara) hungerfordi Jaczewski, 1927: 54. Arctocorixa hungerfordi: Hungerford (1928): pr. 6 (fig. 4). Sigara (Tropocorixa) hungerfordi: Hungerford (1948): 765. Sigara hungerfordi: Jaczewski (1950) apud Bachmann (1981): 108.

Informações sobre os tipos. - Parte dos síntipos foi destruída durante a Segunda Grande Guerra, em 1944 (Bachmann 1981). Três síntipos (dois machos e uma fêmea do Município de Ponta Grossa, Paraná) estão depositados no
SEMC, conforme Hungerford (1948) - que os denomina erradamente de parátipos - e Bachmann (1981). Sem lectótipo designado.

Material examinado. - Rosário do Sul, Distrito de Armada [54 59 $13,8^{\prime} \mathrm{W} / 30^{\circ} 17^{\prime} 34,5$ "S], em ambiente permanente, 19.VII.2006, (L. Maltchik \& C. Stenert): $1 \mathrm{~m}$ (UNISINOS). Soledade [52 $23^{\prime} 19,5^{\prime \prime} \mathrm{W}$ $28^{\circ} 54^{\prime} 51,3$ ”S ], em criadouros sem lâmina d'água, 14.VI.2002, (L. Maltchik \& C. Stenert): $1 \mathrm{~m}$ (UNISINOS)

Redescrição baseada em espécimes do sexo masculino. Biometria (apenas um espécime não danificado). - Comprimento total do corpo: $6,9 \mathrm{~mm}$; largura máxima do corpo: 2,6 $\mathrm{mm}$.

Coloração geral do corpo castanho-escura. Disco pronotal com sete faixas transversais mais ou menos regulares e enegrecidas (Fig. 36). Região ventral do abdome com manchas castanho-escuras (Fig. 38).

Cabeça, tórax e abdome. - Vértice pouco proeminente, não se sobressaindo em relação à borda anterior dos olhos, em vista dorsal (Fig. 36); comprimento do sintilipso menor do que 0,9 vezes a largura da borda posterior de um olho, em vista dorsal; fóvea facial larga e ligeiramente côncava, com pouca pilosidade, alcançando a borda lateral dos olhos, em vista ventral; gena estreita. Disco pronotal com a borda posterior arredondada, em vista dorsal (Fig. 36); metaxifo mais estreito ou tão largo quanto comprido; fêmur das pernas anteriores com área estridulatória pouco desenvolvida, em vista ventral; pala longa e quadrangular, com 33 espinhos, distribuídos em uma fileira que se encurva ligeiramente em sua porção mediana; cinco espinhos apicais da pala ligeiramente maiores que os demais (Fig. 37); comprimento das garras tarsais das pernas médias aproximadamente dois quintos do comprimento do fêmur; comprimento da pilosidade hidrófoba dos fêmures posteriores aproximadamente dois terços de seu comprimento total em vista ventral; comprimento da pilosidade da área pós-nodal igual ou ligeiramente menor que o da área da sutura claval. Estrigilo grande e arredondado, com cinco faixas escuras e regulares, duas um pouco menores; borda posterior do sexto tergito abdominal sem uma expressão caudal em sua metade direita; laterotergito direito do sétimo segmento abdominal apresentando uma saliência bem marcada; lóbulo do sétimo segmento abdominal largo na base, não angulado em suas bordas laterais, afilando-se em direção a borda posterior arredondada, com algumas cerdas compridas dispostas ao longo de sua margem (Fig. $38)$.

Genitália masculina (Fig. 39). - Parâmero direito simples, com a mesma largura em toda sua extensão, sem esporão na região anterior, em vista lateral; região preapical sem dentes ou serrilhado; região apical alongada e aguda.

Distribuição geográfica no Brasil. - Minas Gerais, São Paulo, Paraná e Santa Catarina (Jaczewski 1927; Hungerford 1948; Melo \& Nieser 2004). Essa espécie é registrada pela primeira vez no Estado do Rio Grande do Sul, nos Municípios de Rosário do Sul (Distrito de Armada) e Soledade (Fig. $58)$. 

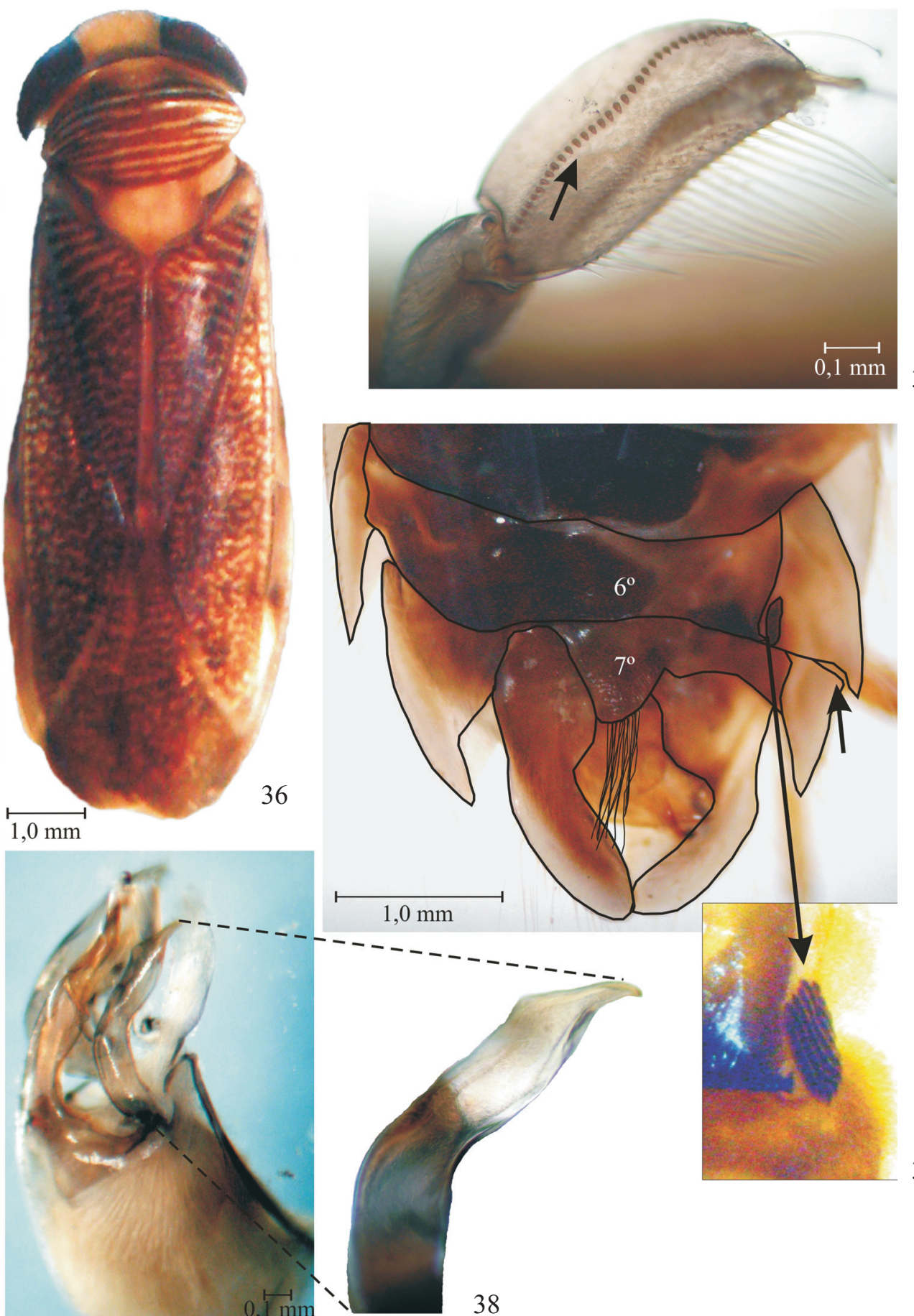

$1,0 \mathrm{~mm}$

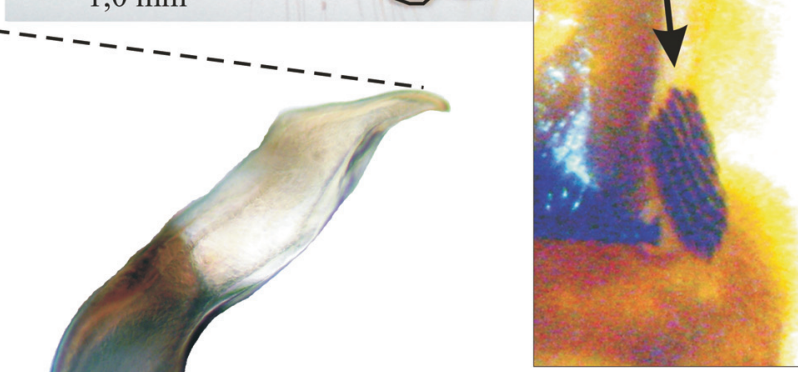

39

Figs. 36-39. Sigara (Tropocorixa) hungerfordi Jaczewski, 1927. 36, Corpo (vista dorsal); 37, Pala de um indivíduo do sexo masculino: seta indicando disposição e forma dos espinhos palares; 38, Abdome de um indivíduo do sexo masculino (vista dorsal): seta indicando detalhes do estrigilo e saliência bem marcada no laterotergito direito do sétimo segmento abdominal; 39, Cápsula genital de um indivíduo do sexo masculino: detalhe do parâmero direito (vista lateral). Abreviatura usada: SA.

Notas comparativas. - Essa espécie é similar à $S .(T$. bachmanni sp. nov. As seguintes características são compartilhadas entre eles: largura do sintilipso menor do que a largura da borda posterior de um olho, metaxifo mais largo do que comprido, genas estreitas. Entretanto, essa duas espécies diferem-se quanto ao formato do ápice do parâmero direi- to, mais curto e ligeiramente curvado, com uma área serrilhada evidente na nova espécie e simples, sem área serrilhada, na região preapical (Fig. 39) em S. (T.) hungerfordi. A forma da pala dos espécimes do sexo masculino descrita neste estudo, bem como o tamanho e a disposição dos espinhos, são consideradas como variações do que se conhece na 
literatura citada. Segundo a descrição de Bachmann (1981), os representantes dessa espécie apresentam a pala longa e moderadamente larga, principalmente na base, com 35 espinhos, sendo os cinco apicais mais compridos, em uma fileira ligeiramente curvada, com uma inflexão no terço distal. Segundo Hungerford (1948), entretanto, a pala apresenta a margem dorsal arredondada e sua parte basal curta, com uma quantidade de espinhos que varia de 28 a 36, dispostos em uma curva pouco acentuada.

\section{Sigara (Tropocorixa) platensis Bachmann, 1962}

$$
\text { (Figs. 40-44, 58) }
$$

Corixa forciceps: Breddin (1897) apud Bachmann (1962b): 15 (non Spinola)

Arctocorisa forciceps: Kirkaldy \& Torre-Bueno (1909): 195

Sigara forciceps: Jaczewski (1927): 58.

Sigara (Sigara) forciceps: Jaczewski (1928) apud Hungerford (1948): 214. Sigara (Tropocorixa) forciceps: Bachmann (1961) apud Bachmann (1981): 16. Sigara (Tropocorixa) platensis Bachmann (1962a): 139.

Informações sobre os tipos. - Spinola (1852) apud Hungerford (1948) descreveu Corixa forciceps Spinola, 1852 com base em um holótipo do sexo masculino do Chile, depositado no Castello de Tassorolo, em Alexandria, Itália. Esse espécime nunca foi estudado nem por Hungerford nem por Bachmann. Bachmann (1981) menciona ter consultado a instituição e ter descoberto que o espécime existe e está em boas condições, mas não pôde obter dados mais detalhados acerca de sua morfologia. Como nunca mais foi registrado nenhum representante dessa espécie no Chile, o autor propôs o novo nome $S$. (T.) platensis, com base apenas nas descrições dos espécimes estudados por Breddin e Jaczewski, e considerou $C$. forciceps uma species inquirenda. Os espécimes no qual essa nova espécie se baseou estão supostamente depositados no ZMH.

Material examinado. - Barra do Quaraí, Parque do Espinilho [57²9'15,27'W/30¹1'40,16”S], Rio Quaraí Chico, fundo argiloso com vegetação, em ambiente permanente,,(L. P. Bernardo \& J. R. I. Ribeiro), 28.III.2009: 9 f (LEBIP 41). Bossoroca [5456’22,3”W/28³5'57,1”S], em ambiente permanente, 15.X.2002, (L. Maltchik \& C. Stenert): 2 m (UNISINOS). Butiá [52॰09'07,4”W/3009'45,9”S], em ambiente permanente, 18.VII.2002, (L. Maltchik \& C. Stenert): $5 \mathrm{f}$ (UNISINOS). Candelária [52 48'02,1'W/29 40'53,1'S], em ambiente intermitente, 25.VII.2002, (L. Maltchik \& C. Stenert): $18 \mathrm{~m}$ (UNISINOS). Cerro Chato [5316'58,4”W/ 29॰42'02,4”S], em ambiente ripário, 25.VII.2002, (L. Maltchik): $2 \mathrm{~m}$ (UNISINOS). Encruzilhada do Sul [52॰34'11,3”W/3048'19,0”S], em ambiente permanente, 25.VII.2002, (L. Maltchik \& C. Stenert): $2 \mathrm{~m}$ (UNISINOS). Guaíba [51²4’13,6”W/30¹3’24,8”S], em ambiente lacustre, 05.IV.2002, (L. Maltchik \& C. Stenert): $1 \mathrm{~m}$ (UNISINOS). Mostardas [50`30'32,2”W/30³7'23,8”S], em ambiente permanente, 2002/2006?, (L. Maltchik \& C. Stenert): $12 \mathrm{~m}$ e $7 \mathrm{f}$ (UNISINOS). Osório [50¹4'41,6”W/ 2952'06,1'S], em ambiente lacustre, 03.V.2002, (L. Maltchik \& C. Stenert): 1 f(UNISINOS). Palmares do Sul [50²9'42,8'W/30'14'53,8'S], 15.III.2002, (L. Maltchik \& C. Stenert): 2 f(UNISINOS); 19.VII.2002: 2 f(UNISINOS). Pantano Grande [52 33 '56,7'W/30 12 '55,9'S], em ambiente intermitente, 18.VII.2002, (L. Maltchik \& C. Stenert): $1 \mathrm{~m}$ (UNISINOS). Rosário do Sul [54 51'24,5"W/30 10'41,7"S], [19.VII.2002], (L. Maltchik): $1 \mathrm{f}$

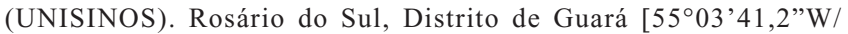
$30^{\circ} 28^{\prime} 43,6$ "S], em ambiente intermitente, 19.VII.2002, (L. Maltchik \& C. Stenert): $1 \mathrm{f}$ (UNISINOS). Santa Maria [5347’31,1”W/2944'58,6”S], em ambiente permanente, 25.VII.2002,,(L. Maltchik): $2 \mathrm{~m}$ e $5 \mathrm{f}$ (UNISINOS). Santiago, Distrito de Ernesto Alves [5444'13,33”W/29²2’2,61"S], 25.X.2009, (L. P. Bernardo, C. Burchard, F. Stefanello e J. R. I. Ribeiro): $1 \mathrm{~m}$ e $7 \mathrm{f}$ (LEBIP 66); em ambiente lótico: $1 \mathrm{f}$ (LEBIP 67); criadouro com plantas aquáticas na beira da estrada: 2 m (LEBIP 115). Santo Ângelo [54¹1'03,2”W/ $28^{\circ} 22^{\prime} 34,0$ 'S ], em criadouro sem lâmina d'água, 04.VII.2002, (L. Maltchik \& C. Stenert): 1 f(UNISINOS). São Francisco [5455'22,7'W/2941'38,8”S], em ambiente intermitente, 12.X.2002, (L. Maltchik \& C. Stenert): $5 \mathrm{~m}$ (UNISINOS). São Gabriel [54²0’31,0 “W/30²0’37,0”S], em revoada nas lâmpadas florescentes e próximo à margem de criadouro temporário, 25.XI.2009, (L. P. Bernardo): 1 f (LEBIP 94); FEPAGRO, lago com fundo argiloso, em ambiente permanente, 17.VI.2009: $1 \mathrm{~m}$ e $1 \mathrm{f}$ (LEBIP 17). São Nicolau $\left[55^{\circ} 09^{\prime} 12,7^{\prime} \mathrm{W} / 28^{\circ} 12^{\prime} 36,5^{\prime} \mathrm{S}\right]$, em ambiente permanente, 06.VII.2002, (L. Maltchik \& C. Stenert): 1 f (UNISINOS). São Sepé [533'07,0”W/3007'07,2”S], em ambiente ripário, 25.VII.2002, (L. Maltchik \& C. Stenert): 2 m (UNISINOS). Tenente Portela [53॰50’06,0”W/ $27^{\circ} 23^{\prime} 18,4$ 'S], em ambiente permanente, 15.VI.2002, (L. Maltchik \& C. Stenert): $1 \mathrm{f}$ (UNISINOS).

Redescrição baseada em espécimes do sexo masculino e feminino. Biometria (machos/fêmeas). - Comprimento total do corpo: 5,3-6,1 mm/5,3-6,3 mm; largura máxima do corpo: $1,7-2,3 \mathrm{~mm} / 2,2-2,7 \mathrm{~mm}$.

Coloração geral do corpo variando de castanho-clara a castanho-escura. Disco pronotal com oito faixas transversais regulares e enegrecidas (Fig. 41).

Cabeça, tórax e abdome. - Vértice proeminente, sobressaindo-se em relação à borda anterior dos olhos, em vista dorsal (Fig. 41); comprimento do sintilipso menor do que 0,9 vezes a largura da borda posterior de um olho, em vista dorsal; fóvea facial larga e ligeiramente côncava, com pouca pilosidade, alcançando a borda lateral dos olhos, em vista ventral; gena muito larga (Fig. 40). Disco pronotal com a borda posterior arredondada, em vista dorsal (Fig. 41); metaxifo mais largo do que comprido; fêmur das pernas anteriores com área estridulatória desenvolvida, em vista ventral; pala longa e quadrangular, com 26 espinhos distribuídos em uma fileira que não se encurva; seis espinhos apicais da pala ligeiramente maiores que os demais (Fig. 42); comprimento das garras tarsais das pernas médias aproximadamente a metade do comprimento do fêmur; comprimento da pilosidade hidrófoba dos fêmures posteriores aproximadamente dois terços de seu comprimento total em vista ventral; comprimento da pilosidade da área pós-nodal igual ou maior que a da área da sutura claval. Estrigilo grande, alongado e arredondado, com o número de faixas escuras e ligeiramente regulares variando de cinco a sete; borda posterior do sexto tergito abdominal sem uma expressão caudal acentuada em sua metade direita; laterotergito direito do sétimo segmento abdominal sem saliência; lóbulo do sétimo segmento abdominal grande e de mesma largura em toda sua extensão, com a borda posterior truncada e de formato quadrangular, com a borda direita apresentando poucas cerdas compridas dispostas ao longo de sua margem (Fig. 43).

Genitália masculina (Fig. 44). - Porção anterior do parâmero direito ligeiramente larga, seguida de um estreitamento na região mediana e uma dilatação na porção apical; esporão ausente em sua região anterior; porção preapical serrilhada; porção mediana com um serrilhado conspícuo; porção apical aguda, curta, com uma crista transparente em vista dorsal. 

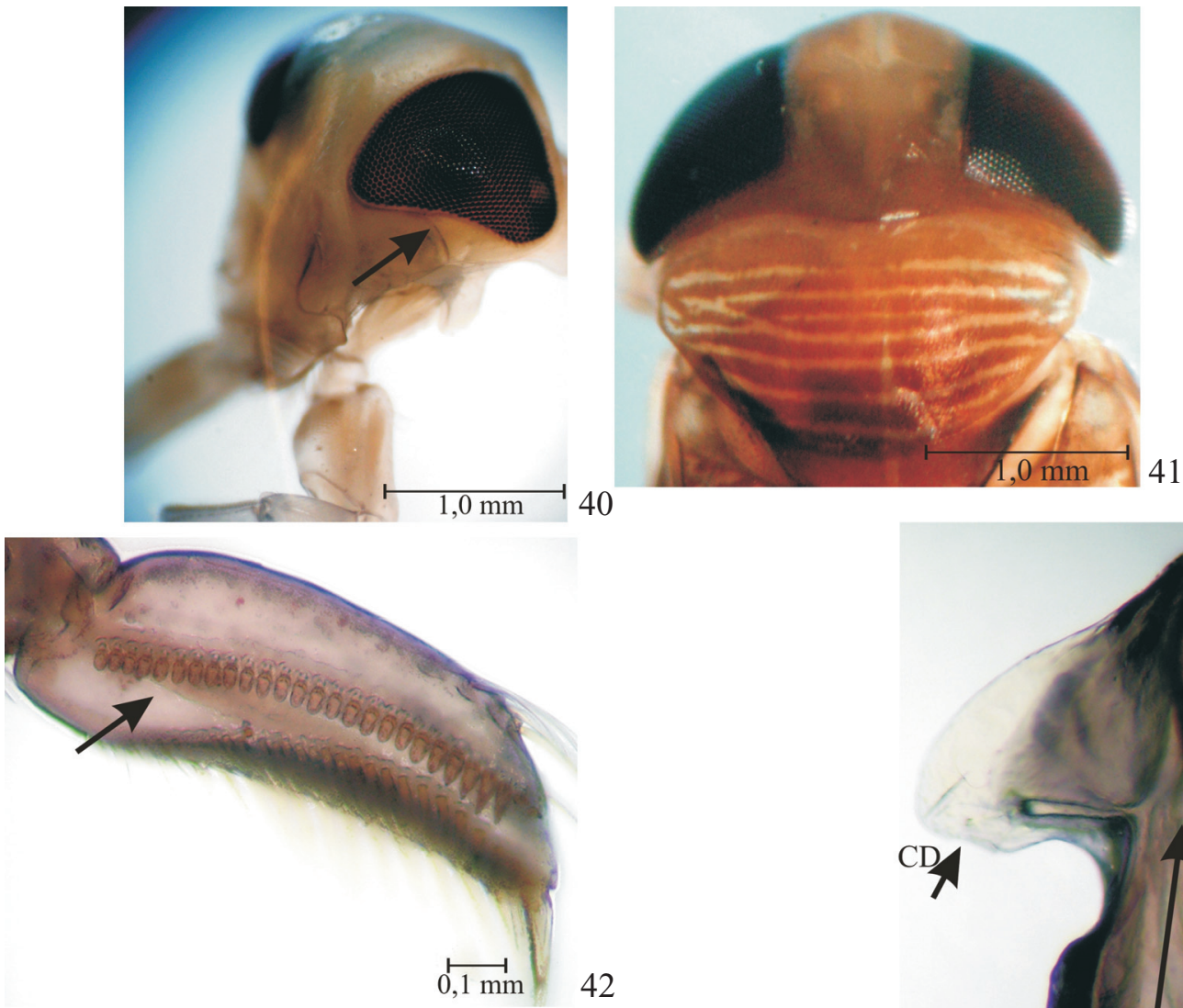

42
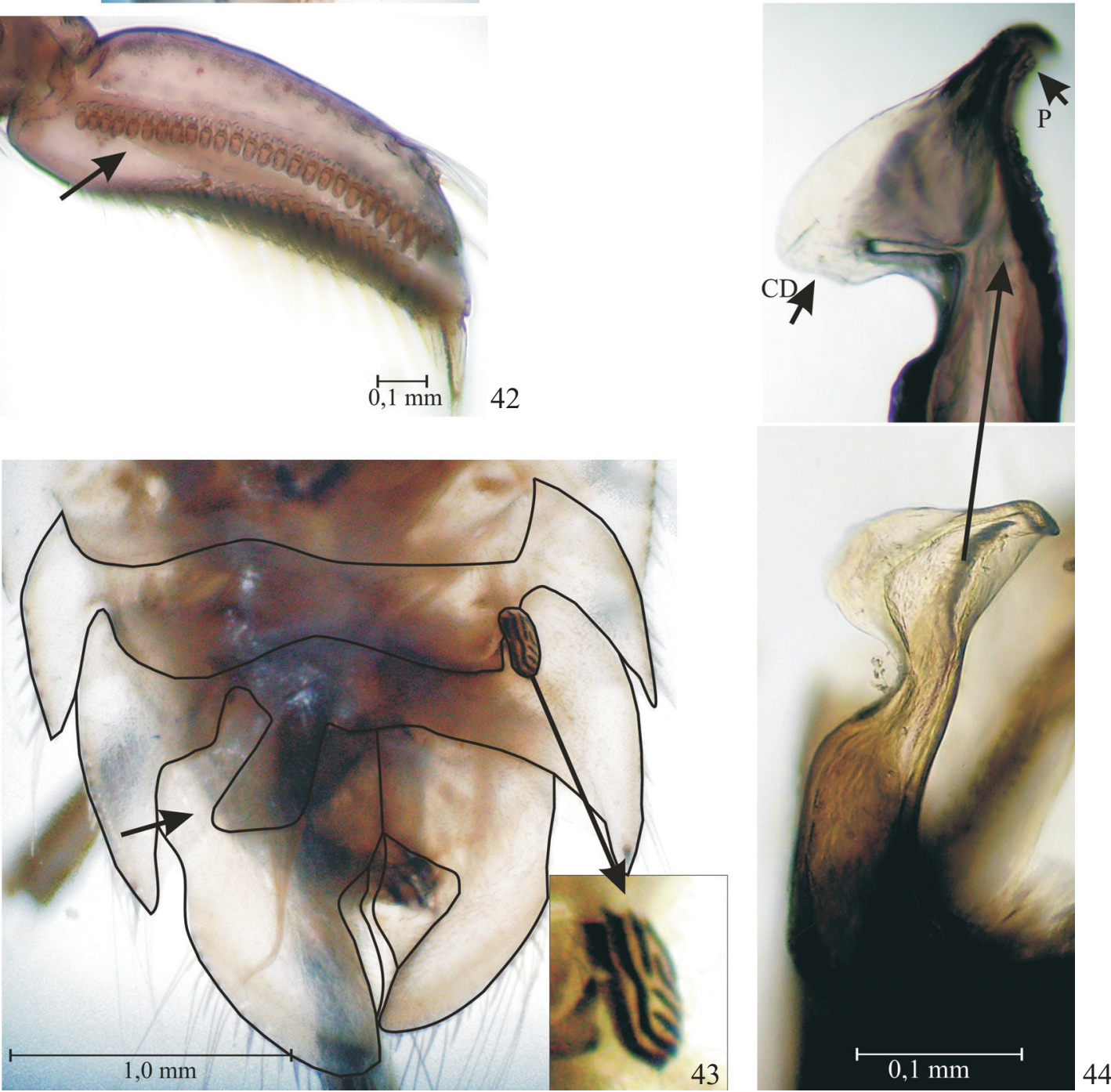

Figs. 40-44. Sigara (Tropocorixa) platensis Bachmann, 1962. 40, Cabeça (vista látero-ventral): seta indicando a gena larga; 41, Cabeça (vista dorsal); 42, Pala de um indivíduo do sexo masculino (vista lateral): seta indicando formato e disposição dos espinhos da pala; 43, Abdome de um indivíduo do sexo masculino (vista dorsal): seta indicando formato do lóbulo do sétimo segmento abdominal e faixas escuras do estrigilo; 44, Parâmero direito (vista lateral) em duas posições diferentes: seta indicando detalhe do ápice do parâmero direito, com região preapical serrilhada, crista dorsal transparente. Abreviaturas usadas: $\mathrm{CD}$, crista dorsal; P, prolongamento apical.

Distribuição geográfica no Brasil. - Minas Gerais, Paraná, Santa Catarina e Rio Grande do Sul (Hungerford 1948; Melo \& Nieser 2004). Essa espécie foi registrada no Estado do Rio
Grande do Sul, pela primeira vez, nos Municípios de Barra do Quaraí, Bossoroca, Butiá, Candelária, Cerro Chato, Encruzilhada do Sul, Guaíba, Guará, Mostardas, Osório, Palmares do 
Sul, Rosário do Sul, Santa Maria, Santiago (Distrito de Ernesto Alves), Santo Ângelo, São Francisco, São Gabriel, São Leopoldo, São Nicolau, São Sepé e Tenente Portela (Fig. 58).

Notas comparativas. - Os representantes dessa espécie são similares aos de $S$. (T.) dita devido às seguintes características compartilhadas entre eles: a largura do sintilipso menor do que 0,9 vezes o comprimento da borda posterior de um olho, o metaxifo mais largo do que comprido e pela presença de uma crista na porção apical do parâmero direito dos espécimes do sexo masculino (compare Figs. 32 e 44). Entretanto, S. (T.) platensis difere-se de $S$. (T.) dita pelo aspecto geral do parâmero direito, que apresenta um estreitamento em sua porção mediana na primeira espécie e uma crista menos elevada em sua porção apical na segunda espécie (Figs. 32-34, 44). Essa espécie podem ser distinguida das outras espécies deste estudo pela gena bastante larga e o lóbulo do sétimo segmento abdominal com um aspecto retangular, com seu ápice truncado (Fig. 43).

\section{Sigara (Tropocorixa) schadei (Hungerford, 1928)}

$$
\text { (Figs. 45-48, 58) }
$$

Arctocorixa rubyi var. schadei Hungerford (1928): 176.

Sigara schadei: Ruffinelli \& Pirán (1959): 48.

Sigara (Tropocorixa) schadei: Hungerford (1948): 764.

Informações sobre os tipos. - Hungerford (1948) descreveu essa espécie com base em um holótipo do sexo masculino e dois parátipos, um do sexo masculino e outro do sexo feminino, coligidos em Villa Rica, Paraguai e depositado no SEMC.
Material examinado. - São Gabriel [54²1’45,55”W/30²0’1,81”S], em revoada em lâmpadas fluorescentes, 25.XI.2009, (L. P. Bernardo): $1 \mathrm{~m}$ (LEBIP 22); em criadouro na beira de estrada com plantas aquáticas: $4 \mathrm{f}$ (LEBIP 64).

Descrição baseada em um único espécime do sexo masculino. Biometria. - Comprimento total do corpo: 6,9 mm; largura máxima do corpo: $2,5 \mathrm{~mm}$.

Coloração geral do corpo castanho-clara. Disco pronotal com seis faixas transversais enegrecidas, tornando-se difusas ao aproximarem-se da borda anterior (Figs. 45-46). Porções dorsais do tórax e do abdome ligeiramente enegrecidas (Fig. 45).

Cabeça, tórax e abdome. - Vértice pouco proeminente, sobressaindo-se ligeiramente em relação à borda anterior dos olhos em vista dorsal (Fig. 46); comprimento do sintilipso maior do que 0,9 vezes a largura da borda posterior de um olho, em vista dorsal; fóvea facial ligeiramente côncava, mal definida, não alcançando a borda lateral dos olhos, em vista ventral; gena estreita. Disco pronotal com borda posterior apresentando uma inflexão, em vista dorsal (Fig. 46); metaxifo mais estreito que comprido; fêmur das pernas anteriores com área estridulatória pouco desenvolvida, em vista ventral; pala dos espécimes do sexo masculino longa e quadrangular, com 38 espinhos, distribuídos em uma fileira que se encurva ligeiramente em sua porção distal; oito espinhos apicais um pouco maiores que os demais (Fig. 47); comprimento da garra tarsal das pernas médias aproximadamente três quintos do comprimento do fêmur; comprimento da pilosidade hidrófoba dos fêmures posteriores cobrindo apro-
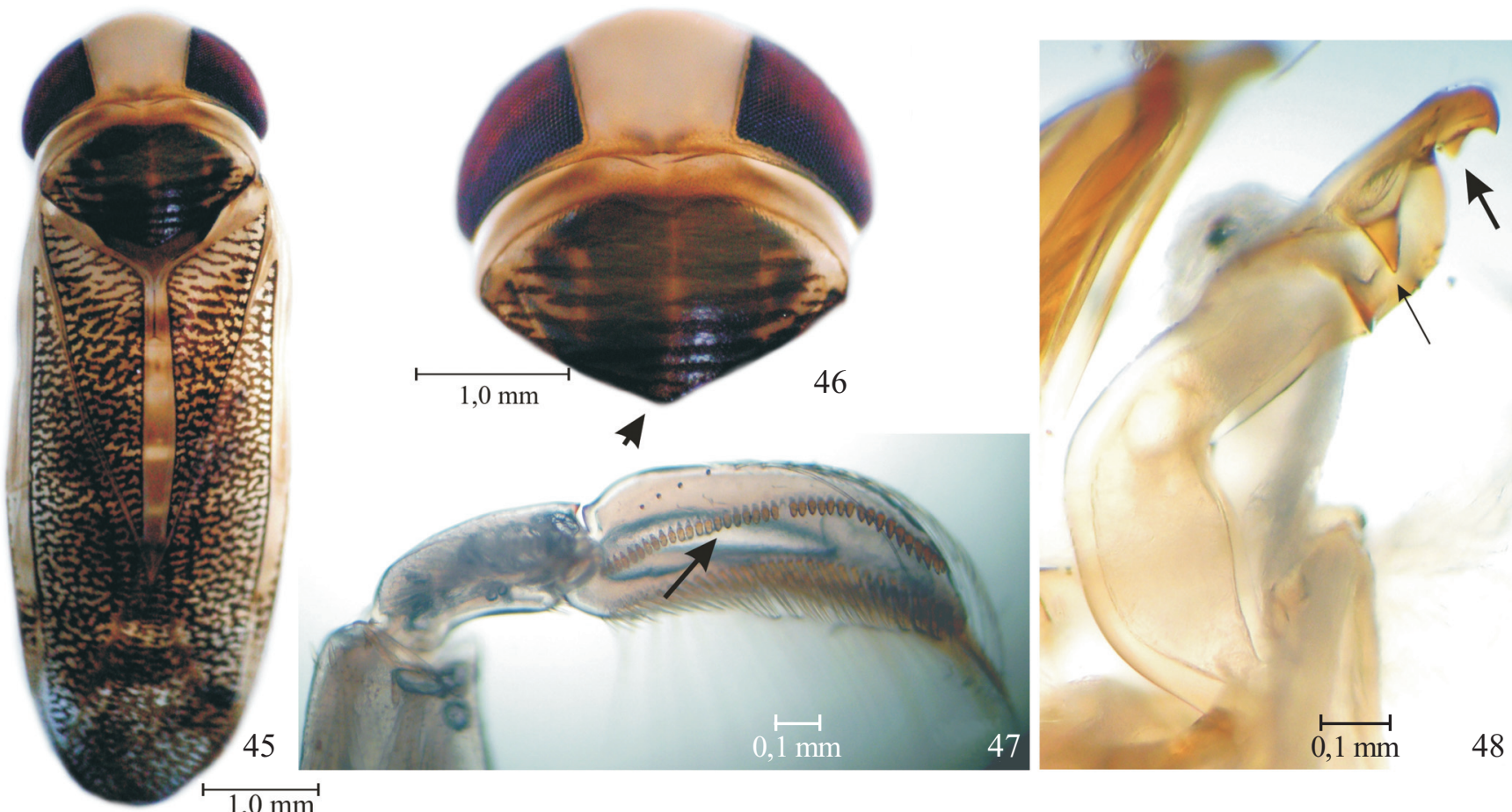

Figs. 45-48. Sigara (Tropocorixa) schadei (Hungerford, 1928). 45, Corpo (vista dorsal); 46, Cabeça e disco pronotal (vista dorsal): seta indicando inflexão na borda posterior do disco pronotal; 47, Pala de um indivíduo do sexo masculino (vista lateral): seta indicando espinhos palares; 48, Parâmero direito de um indivíduo do sexo masculino: seta indicando dentes na região apical e as duas cristas de direção oposta ao ápice. 
ximadamente a metade de seu comprimento total em vista ventral; comprimento da pilosidade da área pós-nodal maior do que a da área da sutura claval. [Estrigilo mediano, elíptico, formado seis faixas escuras e regulares; borda posterior do sexto tergito abdominal com uma ampla expressão caudal em sua metade direita, quase atingindo a borda posterior do sétimo segmento; lóbulo do sétimo segmento abdominal grande e largo, com poucas cerdas compridas dispostas ao longo de sua margem].

Genitália masculina (Fig. 48). - Região anterior do parâmero direito larga, afilando-se e encurvando-se em sua região mediana; esporão ausente em sua região anterior; região preapical do parâmero direito apresentando duas cristas com direções opostas ao ápice; porção apical com uma pequena projeção apresentando dois grandes dentes.

Distribuição geográfica no Brasil. - Essa espécie é registrada pela primeira vez no país. Sua ocorrência no Estado do Rio Grande do Sul é assinalada no Município de São Gabriel (Fig. 57).

Notas comparativas. - Os representantes dessa espécie são similares aos de $S$. denseconscripta devido às seguintes características compartilhadas entre eles: a largura do sintilipso maior do que 0,9 vezes a largura da borda posterior de um olho, o metaxifo mais comprido do que largo e a gena estreita. Entretanto, ambas são diferenciadas pelo aspecto da borda posterior do disco pronotal, mais arredondada em $S$. (T.) denseconscripta (Fig. 26) e com inflexão em $S$. (T.) schadei (Fig. 46); pelo aspecto da pala dos espécimes do sexo masculino, subtriangular e com os espinhos apicais muito maiores que os demais na primeira espécie (Fig. 27)e quadrangular, com os espinhos apicais ligeiramente maiores que os demais na segunda espécie (Fig. 47). Sigara (T.) denseconscripta ainda pode diferenciar-se de $S$. (T.) schadei pelo formato dilatado do parâmero direito de seus representantes do sexo masculino, com uma forma aproximada de "C" (Fig. 28). Segundo Hungerford (1928, 1948), os representantes do sexo masculino dessa espécie apresentam o estrigilo com quatro estrias e o número de espinhos da pala variando de 38 a 40. Seriam necessárias mais coletas para uma melhor avaliação da amplitude de variação dessa característica.

\section{Sigara (Tropocorixa) townsendi (Hungerford, 1928)}

$$
\text { (Figs. 49-54, 56, 58) }
$$

Arctocoprixa chrostowskii var. townsendi Hungerford, 1928:177. Sigara (Tropocorixa) townsendi: Hungerford (1948): 765.

Informações sobre o tipo. - Hungerford (1928) descreveu essa espécie com base em um holótipo do sexo masculino coligido em São Paulo, Brasil e depositado no SEMC.

Material examinado. - Mostardas [50³0'32,2"W/ $30^{\circ} 37^{\prime} 23,8^{\prime}$ 'S ], em ambiente permanente, 15.III.2002/ VI.2006?, (L. Maltchik \& C. Stenert): $2 \mathrm{~m}$ (UNISINOS).

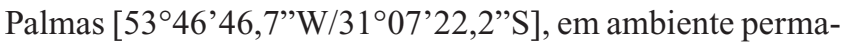
nente, 21.IV..2002 (L. Maltchik): $1 \mathrm{~m}$ (UNISINOS). São
Caetano [51 $51^{\prime} 06,7^{\prime \prime} \mathrm{W} / 31^{\circ} 52^{\prime} 36,7^{\prime}$ 'S ], em ambiente permanente, 16.III.2002 (L. Maltchik): 2 m (UNISINOS). São Francisco [5455'22,7'W/2941'38,8's], em ambiente intermitente, 12.X.2002, (L. Maltchik): $1 \mathrm{~m}$ (UNISINOS).

Redescrição baseada em espécimes do sexo masculino. Biometria. - Comprimento total do corpo: 5,1-5,8 mm; largura máxima do corpo: 1,7-2,2 $\mathrm{mm}$.

Coloração geral do corpo variando de castanho-clara a castanho-escura. Disco pronotal com o número de faixas transversais variando de seis a sete, ligeiramente regulares e enegrecidas (Fig. 49).

Cabeça, tórax e abdome. - Vértice dos espécimes do sexo masculino pouco proeminente, não se sobressaindo em relação à borda anterior dos olhos, em vista dorsal (Fig. 49); comprimento do sintilipso menor do que 0,9 vezes a largura da borda posterior de um olho, em vista dorsal; fóvea facial larga e ligeiramente côncava, com pouca pilosidade, alcançando a borda lateral dos olhos, em vista ventral; gena estreita. Disco pronotal com a borda posterior com inflexão, em vista dorsal; metaxifo mais largo do que comprido; fêmur das pernas anteriores com área estridulatória desenvolvida, em vista ventral; pala dos espécimes do sexo masculino curta e quadrangular (Fig. 53) e, em alguns outros espécimes, ligeiramente subtriangular, apresentando a base mais larga do que o ápice (Fig. 51); pala com o número de espinhos variando entre 27 e 28; distribuídos em uma fileira que se encurva ligeiramente em sua porção distal; seis espinhos apicais da pala maiores que os demais (Fig. 53); comprimento das garras tarsais das pernas médias 0,4 vezes o comprimento do fêmur; comprimento da pilosidade hidrófoba dos fêmures posteriores aproximadamente a metade de seus comprimento total em vista ventral; comprimento da pilosidade da área pós-nodal igual ou ligeiramente mais curta que a da área da sutura claval. Estrigilo grande ou ligeiramente grande e arredondado, com o número de faixas escuras, ligeiramente regulares, variando de quatro a sete (Fig. 49); borda posterior do sexto tergito abdominal com um prolongamento caudal acentuado em sua metade direita, quase atingindo a borda posterior do sétimo segmento; laterotergito direito do sétimo segmento abdominal com uma saliência bem marcada, afilando-se em direção a borda posterior arredondada, apresentando cerdas compridas e curtas dispostas ao longo de sua margem; lóbulo do sétimo segmento abdominal grande, largo em sua base, afilando-se em direção à sua borda posterior; borda direita apresentando poucas cerdas compridas (Fig. 50).

Genitália masculina (Figs. 52, 54). - Região anterior do parâmero direito larga, seguida de um estreitamento abrupto na porção apical; esporão ausente em sua região anterior; porção preapical lisa, não serrilhada; número de dentes da região preapical do parâmero direito superior a sete; região apical com um prolongamento em forma de gancho longo.

Distribuição geográfica no Brasil. - São Paulo (Hungerford, 1948). Essa espécie é registrada no Estado do Rio Grande do Sul pela primeira vez, nos Municípios de Mostardas, Palmas e São Caetano (Fig. 58). 


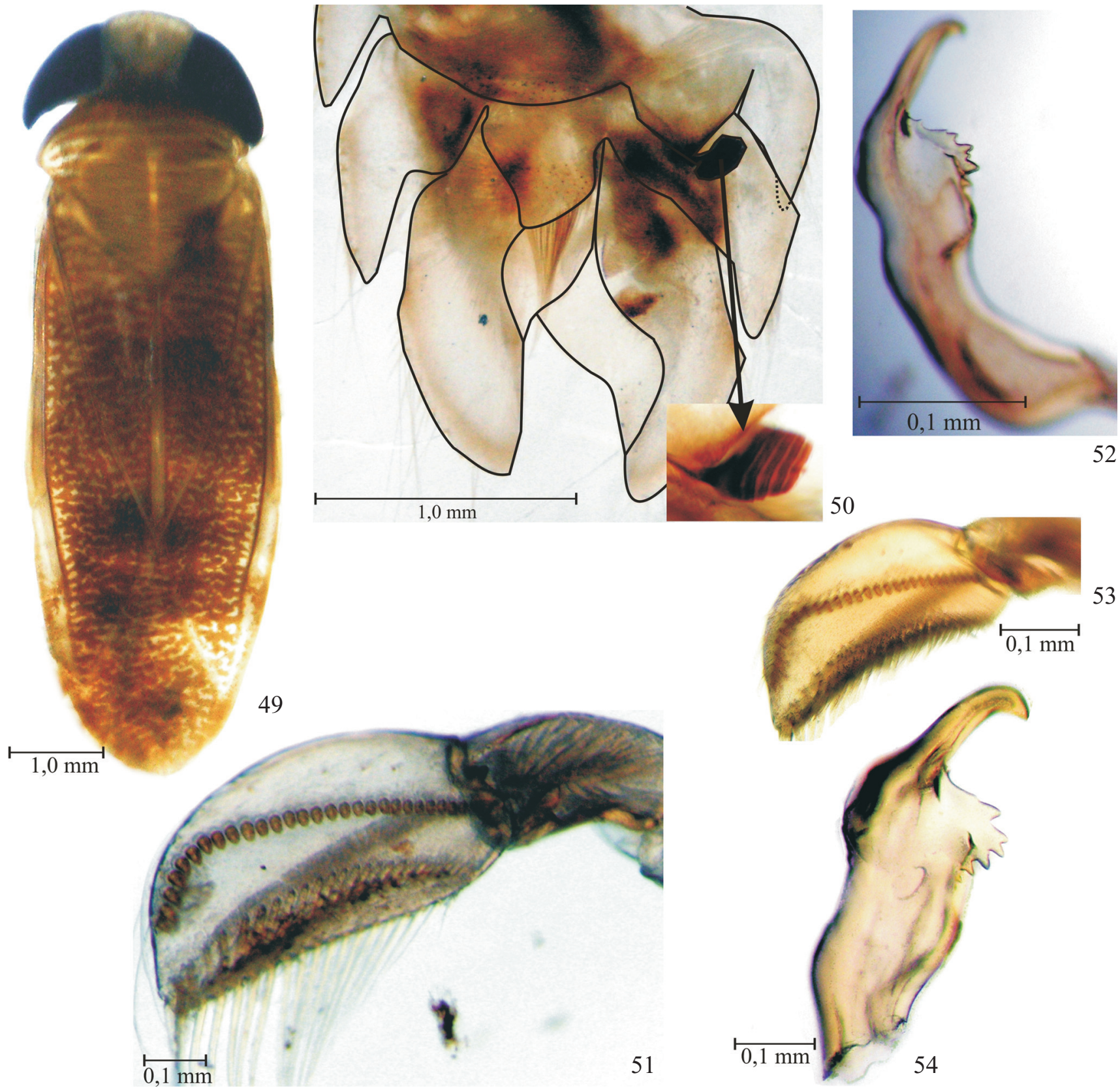

Figs. 49-54. Sigara (Tropocorixa) townsendi (Hungerford, 1928). 49, Corpo (vista dorsal); 50, Abdome de um indivíduo do sexo masculino (vista dorsal): seta indicando ângulo do lóbulo do sétimo segmento abdominal e detalhe do estrigilo; 51-52, Espécime do sexo masculino coligido no Município de Mostardas, Rio Grande do Sul (variação a); 51, Pala; 52, Parâmero direito; 53-54, Espécime do sexo masculino coligido no Município de Mostardas (variação b); 53, Pala; 54, Parâmero direito.

Variações (Fig. 56). - Foram encontradas variações no número de espinhos e no formato das palas, no número e na disposição dos dentes da região preapical do parâmero direito e no grau de desenvolvimento do exporão proximal.

Notas comparativas. - Os representantes dessa espécie são similares ao de $S$. (T.) chrostowskii devido às seguintes características compartilhadas entre eles: largura do sintilipso menor do que 0,9 vezes a largura da borda posterior de um olho, metaxifo mais largo do que comprido, gena estreita e o aspecto alongado, estreito e em forma de gancho do ápice do parâmero direito dos representantes do sexo masculino (Figs. 52, 54). Entretanto, segundo Hungerford (1948), S. (T.) townsendi difere-se de $S$. (T.) chrostowskii pela coloração geral do corpo mais escura, pelo menor porte de seus representantes e pela presença de uma maior e mais conspícua área serrilhada, com um maior número de dentes na região preapical do parâmero direito dos machos (Figs. 24, 52, 54).

Os espécimes de $S$. (T.) townsendi foram ilustrados com maior detalhamento pela primeira vez neste estudo. Como em S. (T.) chrostowskii, seria esperado que os representantes 


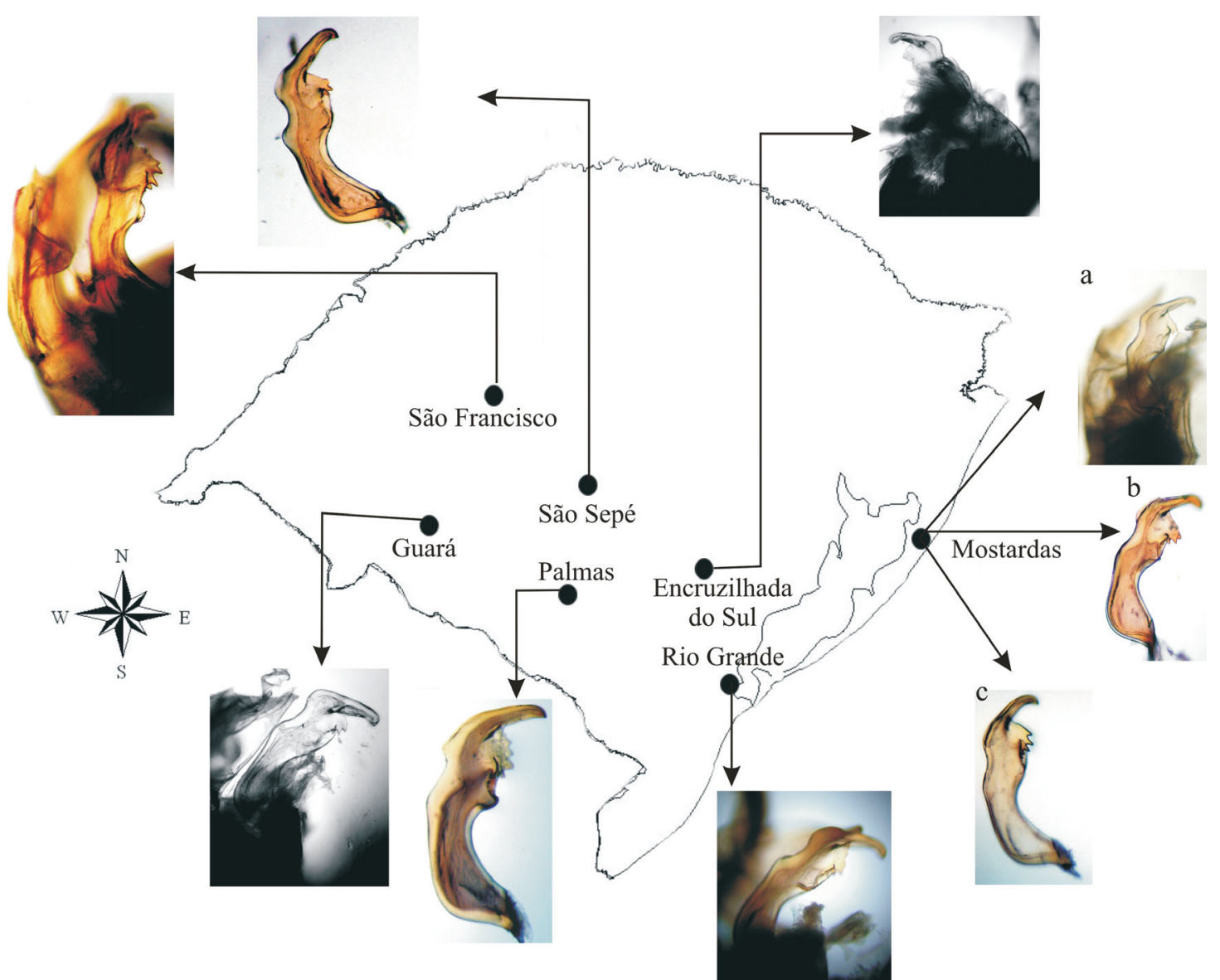

Fig. 55. Distribuição de diferentes exemplares de Sigara (Tropocorixa) chrostowskii Jaczewski, 1927 no Estado do Rio Grande do Sul e a amplitude de variação encontrada no número de dentes do parâmero direito dos indivíduos do sexo masculino. Exemplar de Encruzilhada do Sul com três dentes no parâmero; exemplar de Guará, de Mostardas (a, b, c), Palmas, Rio Grande, São Francisco e São Sepé com cinco dentes no parâmero.

dessa espécie apresentassem variações no comprimento das garras tarsais das pernas médias em relação ao comprimento total do fêmur, bem como na inflexão da borda posterior do disco pronotal. Isso não acontece, entretanto, conforme a Tabela I. Segundo Bachmann (1981), o número de dentes na porção preapical do parâmero direito é maior que sete nessa espécie. Entretanto, o autor menciona nunca ter visto espécimes do sexo masculino de $S$. (T.) townsendi. Além disso, as ilustrações de Hungerford (1948) não demonstram muito bem o serrilhado, o que torna a tarefa de saber quantos dentes apresenta a região preapical do parâmero direito dos espécimes do sexo masculino muito difícil. Neste estudo, foram encontrados espécimes com número de dentes variando de oito a 12, (Fig. 56). Não houve relação entre número de dentes dessa região do parâmero de espécimes de diferentes localidades do Estado com o número de espinhos e formato da pala dos machos, nem entre relação entre o comprimento da garra tarsal e o comprimento do fêmur das pernas medianas, o grau de inflexão da borda posterior do disco pronotal e o número de faixas enegrecidas do estrigilo (Tabela I), Assim, todos os espécimes com número de dentes acima de sete foram tratados, neste estudo, como representantes de $S$. (T.) townsendi.
Chave dicotômica de identificação para machos das espécies de Sigara Fabricius ocorrentes no Estado do Rio Grande do Sul, Brasil [modificada de Hungerford (1948) e Bachmann (1981)]

1a. Comprimento do sintilipso igual ou maior que 0,9 vezes o comprimento da borda posterior de um olho (Fig. 1); metaxifo mais estreito que comprido (Fig. 9) .............. 2

1b. Comprimento do sintilipso menor do que 0.9 vezes o comprimento da borda posterior de um olho; metaxifo mais largo que comprido 3

2a (1a). Disco pronotal com borda posterior arredondada, sem inflexão (Fig. 2); parâmero direito com sua porção apical aguda, com uma forma aproximada de "C", em vista lateral (Fig. 28) .....S. (T.) densecosncripta (Figs. 25-28)

2b. Disco pronotal com uma inflexão em sua borda posterior (Fig. 1); parâmero direito apresentando duas cristas com direções opostas ao ápice, em vista ventral, porção apical com uma pequena projeção apresentando dois grandes dentes (Fig. 48) . S. (T.) schadei (Figs. 45-48)

3a (1b). Gena larga (Fig. 6); lóbulo do sétimo segmento abdominal quadrangular, com a borda posterior truncada (Fig. 43) ................................... . (T.) platensis (Figs. 40-44) 


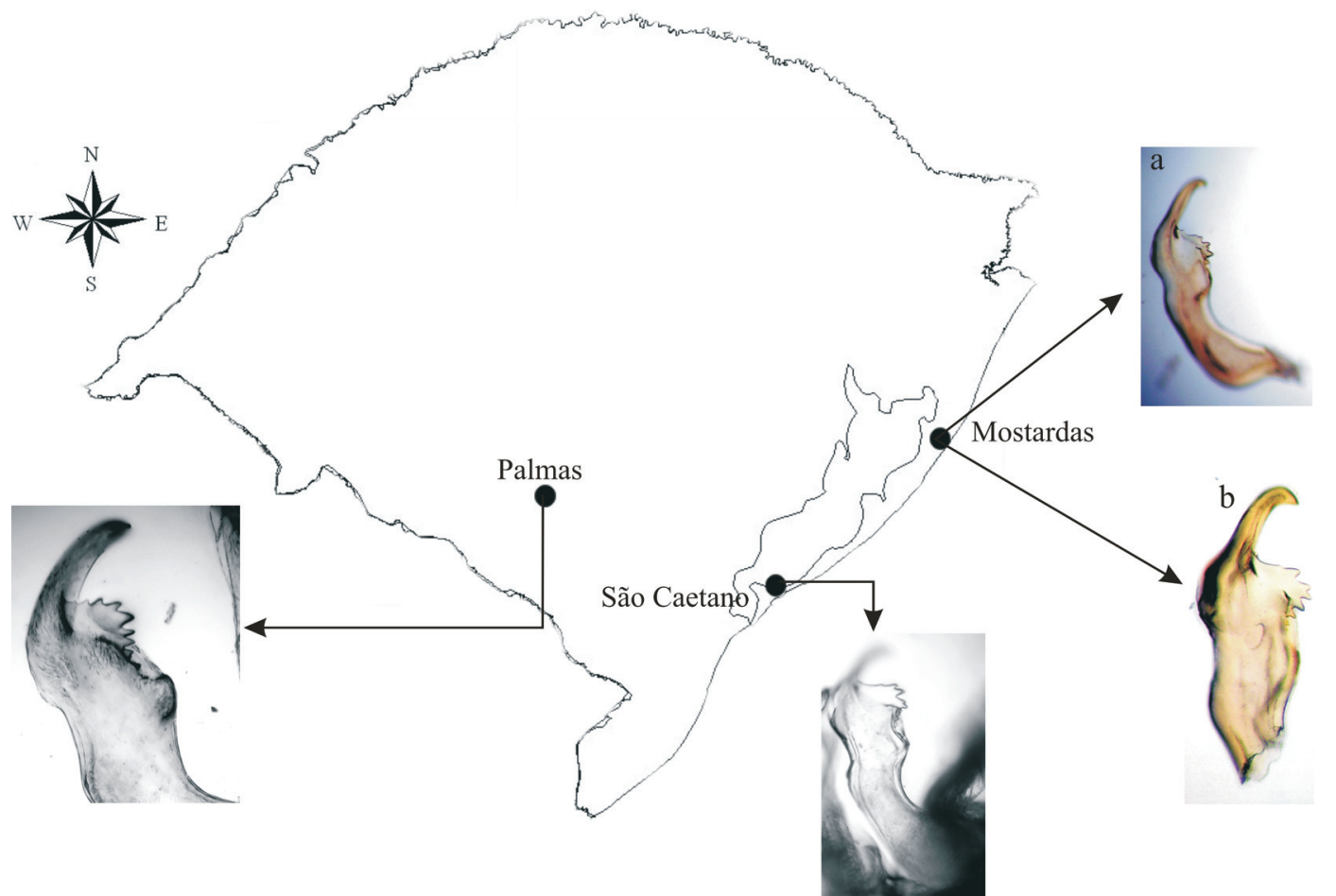

Fig. 56. Distribuição de diferentes exemplares de Sigara (Tropocorixa) townsendi (Hungerford, 1928) no Estado do Rio Grande do Sul e a amplitude de variação encontrada no número de dentes do parâmero direito dos indivíduos do sexo masculino. Exemplares de Mostardas (a, b) com oito dentes no parâmero; exemplar de Palmas com 12 dentes no parâmero; exemplar de São Caetano com oito dentes no parâmero.

3b. Gena estreita (Fig. 5), lóbulo do sétimo segmento abdominal de forma variável, nunca como acima

4a (3b). Disco pronotal com o número de faixas transversais enegrecidas variando de nove a 10 (Figs. 29-30); parâmero direito largo em quase toda sua extensão, com a porção apical obtusa, raramente aguda, em vista lateral (Figs. 3234) . S. (T.) dita (Figs. 29-35)

4b. Disco pronotal com o número de faixas transversais enegrecidas variando de cinco a seis (como nas Figs. 14, 36); parâmero direito sempre com a porção apical aguda (como nas Figs. 17, 39) .. 5

5a (4b). Disco pronotal com a borda posterior arredondada (como na Fig. 14); lóbulo do sétimo segmento abdominal largo na base, sem apresentar ângulo em sua borda lateral esquerda (como na Fig. 16)

5b. Disco pronotal com a borda posterior não arredondada; se arredondada, então o parâmero direito possui dentes evidentes na região preapical (como nas Figs. 24, 52, 54); lóbulo do sétimo segmento abdominal largo na base e apresentando ângulo em sua borda lateral esquerda (como nas Figs. 23, 50) 7

6a (5a). Laterotergito direito do sétimo segmento abdominal apresentando uma saliência bem marcada em sua porção mediana (Fig. 38); parâmero direito simples, com a mesma largura em toda sua extensão; região preapical sem dentes ou serrilhado (Fig. 39)

S. (T.) hungerfordi (Figs. 36-39) 6b. Laterotergito direito do sétimo segmento abdominal sem saliência em sua porção mediana (Fig. 16); parâmero direito com a região basal ligeiramente larga, afilando-se em sua porção mediana e alargando-se novamente em seu ápice; região apical com serrilhados e com uma pequena área em forma de crista desenvolvida (Fig. 17)

S. (T.) bachmanni Bernardo \& Ribeiro, sp. nov. (Figs. 14-17)

$7 \mathrm{a}$ (5b). Parâmero direito com um esporão ligeiramente desenvolvido em sua região anterior; região preapical com o número de dentes variando de três a sete (Fig. 24)

S. (T.) chrostowskii (Figs. 18-24)

7b. Parâmero direito sem esporão em sua região anterior; região preapical com o número de dentes sempre superior a sete e podendo chegar até 12 (Figs. 52 e 54)

S. (T.) townsendi (Figs. 49-54)

\section{DISCUSSÃO}

Das espécies com registro no Estado do Rio Grande do Sul, S. (T.) chrostowskii, S. (T.) dita e $S$. (T.) townsendi apresentaram variações morfológicas, já observadas e descritas por diferentes autores (Hungerford 1948; Jaczewski 1927; Bachmann 1981). Um sumário dessas variações observadas em espécimes de diferentes localidades de $S$. (T.) chrostowskii e $S$. (T.) townsendi é apresentado na Tabela I.

Por outro lado, a semelhança morfológica entre os representantes de $S$. (T.) chrostowskii e $S$. (T.) townsendi (consideradas espécies crípticas) torna difícil a identificação dessas 


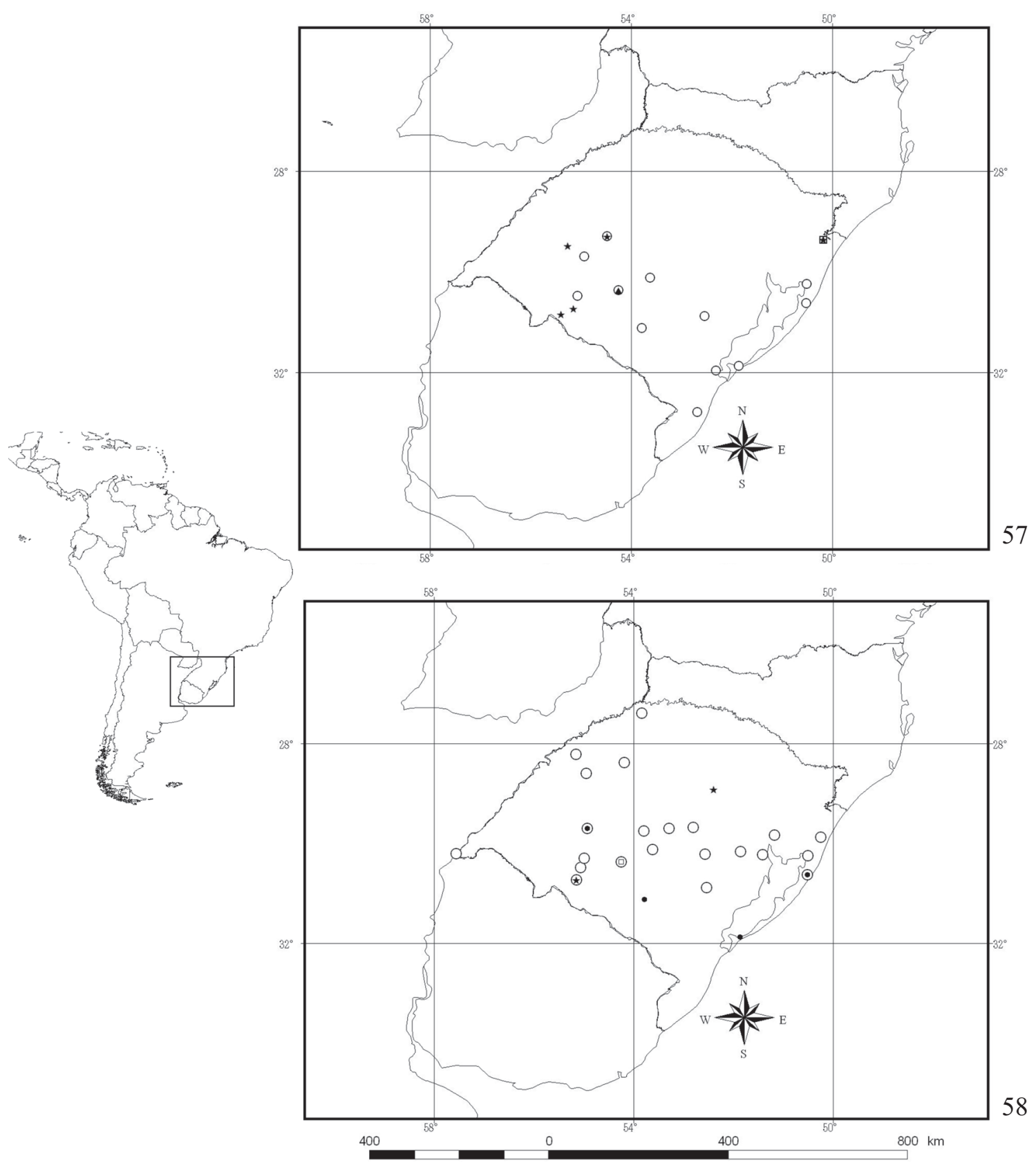

Figs. 57-58. Mapa do Rio Grande do Sul, Brasil mostrando a distribuição geográfica das espécies de Sigara Fabricius, 1775. 57, $\square=$ Sigara (Tropocorixa) bachmanni Bernardo \& Ribeiro, sp. nov.; $O=S$. (T.) chrostowskii Jaczewski, 1927; $\boldsymbol{\Delta}=S$. (T.) denseconscripta (Breddin, 1897); $\star=S$. (T.) dita Jaczewski, 1927; 58, $\star=$ Sigara (Tropocorixa) hungerfordi Jaczewski, 1927; $\square=S$. (T.) schadei (Hungerford, 1928); $\bullet$ S. (T.) townsendi $($ Hungerford, 1928); O = S. (T.) platensis Bachmann, 1962.

espécies, principalmente com base em espécimes do sexo feminino. Hungerford (1948) descreveu $S$. (T.) brachypala e $S$. (T.) townsendi como variedades de $S$. (T.) chrostowski, e a diferenciação dessas espécies foi feita com base em características da pala dos representantes do sexo masculino, do sexto tergito abdominal, do lóbulo do sétimo segmento abdominal e da região preapical do parâmero direito e da coloração. Uma hipótese para a gama de variações encontrada poderia ser a de que pressões seletivas parecem atuar mais veementemente em grupos cujas fêmeas acasalam-se com muitos machos em uma mesma estação reprodutiva, sugerindo que mecanismos de seleção sexual pós-copulatórios estejam promovendo divergências morfológicas drásticas na genitália masculina e, por outro lado, de forma mais discreta em outros traços morfológicos, como a forma do corpo (Hosken \& Stockley 2004). O que é produzido a partir desse fenômeno é um aumento na similaridade geral do corpo dos representantes dessas espécies, tornando-as consideravelmente crípticas.

Sigara (T.) brachypala foi sinonimizada por Bachmann (1981) com base na possibilidade dessa espécie tratar-se de 
uma variação morfológica de $S$. (T.) chrostowskii e considerou o tipo dessa espécie um espécime com um caso extremo dessa variação intra-específica. Em relação à $S$. (T.) townsendi, não foi estabelecida a sinonímia com $S$. (T.) chrostowskii, pois o autor não encontrou exemplares que pudessem ser atribuídos a essa espécie, conforme já mencionado anteriormente.

Diante do que foi exposto e das características que foram observadas neste estudo a respeito de $S$. (T.) chrostowskii e $S$. (T.) townsendi, acredita-se que essas duas espécies façam parte de um complexo de espécies formado por essas espécies e por $S$. (T.) brachypala, diante da natureza confusa da taxonomia de $S$. (T.) chrostowskii e da amplitude de variação dessa espécie. Entretanto, para uma melhor definição, seria necessário realizar análises mais elaboradas num contexto filogeográfico, com o uso de ferramentas moleculares. Portanto, o número de dentes da região preapical do parâmero direito dos representantes do sexo masculino é ainda a característica morfológica mais indicada como um critério para a diferenciação dessas duas espécies, visto que foram encontrados representantes de S. (T.) townsendi apresentando até 12 dentes, condição nunca observada por Bachmann (1981). As demais variações morfológicas, tais como no formato e número de espinhos da pala, no número de bandas no disco pronotal, e no número de bandas do estrigilo, foram tratadas aqui como variações individuais nas duas espécies e não apresentaram alguma relação entre si, inclusive quando relacionadas a diferentes regiões do Rio Grande do Sul (Figs. 55-56).

\section{AGRADECIMENTOS}

Ao Dr. Axel O. Bachmann (Museo Argentino de Ciencias Naturales "Bernardino Rivadavia”, Buenos Aires, Argentina) pelos comentários sobre a validade de algumas espécies, ao IBAMA/ICMBio (Instituto Brasileiro do Meio Ambiente - Instituto Chico Mendes de Conservação da Biodiversidade) por conceder a licença de coleta n.14583-1/2009. Este trabalho foi financiado em parte pelo PBDA/UNIPAMPA (Programa de Bolsas de Desenvolvimento Acadêmico).

\section{REFERÊNCIAS}

Arnett-Jr, R. H.; Samuelson, G. A. \& G. M. Nishida. 1993. The insect and spider collections of the world. Gainesville. Sandhill Crane Press, Inc., 2nd edition. vi+310 p.

Bachmann, A. O. 1962a. Catálogo de las Corixidae de la República Argentina (Insecta, Hemiptera). Neotropica 8: 15-25.

Bachmann, A. O. 1962b. Notas sobre Corixidae (Hemiptera) (Tercera serie). Acta Zoologica Lilloana 18: 139-145.

Bachmann, A. O. 1981. Insecta Hemiptera Corixidae, p. 1-270. In: R. A. Ringuelet (ed.). Fauna de Agua Dulce de la República Argentina, Volumen 35. Buenos Aires, FECIC, 270 p.

China, W. E. 1943. The generic names of the British Hemiptera-Heteroptera, with a check list of the British species. Part 8. The Generic Names of British Insects 1: 209-342.

Fabricius, J. C. 1775. Systema Entomologiae, Sistens Insectorum Classes, Ordines, Genera, Species, Adjectis, Synonymis, Locis, Descriptionibus, Observationibus. Flensburgi \& Lipsiae. Officina Libraria Kortii. $\mathrm{xxx}+832$ p.
Hadley, A. 2010. CombineZP. Image stacking software. <http:// www.hadleyweb.pwp.blueyonder.co.uk/CZP/Installation.htm> (Acessado em 21 de novembro de 2011).

Heckman, C. W. 2011. Encyclopedia of South American aquatic insects: Hemiptera - Heteroptera. Illustrated keys to known families, genera, and species in South America. New York. Springer. viii+679 p.

Hosken, D. J. \& Stockley, P. 2004. Sexual selection and genital evolution. Trends in Ecology and Evolution 19: 87-93.

Hungerford, H. B. 1928. Some South American Corixidae. Bulletin of the Brooklyn Entomological Society 23: 175-184.

Hungerford, H. B. 1948. The Corixidae of the Western Hemisphere (Hemiptera). University of Kansas Science Bulletin 32: 1-827.

ICZN (International Commission on Zoological Nomenclature) 1999. International Code of Zoological Nomenclature. London. 4th Edition, The International Trust for Zoological Nomenclature. xxix $+306 \mathrm{p}$.

Jaczewski, T. 1927. Corixidae from the State of Paraná. Annales Zoologici Musei Polonici Historiae Naturalis 6: 39-60.

Jaczewski, T. 1928. Notonectidae from the State of Paraná. Prace Panstwowego Muzeum Zoologicznego 7: 121-136.

Jaczewski, T. 1931. Die Corixiden (Conxidae, Heteroptera) des Zoologischen Staatsinstituts und Zoologischen Museums in Hamburg. Mitteilungen aus dem Zoologischen Staatsinstitut und Zoologischen Museum 44: 140-148.

Kirkaldy, G. W. \& J. R. de la Torre-Bueno. 1909. A catalogue of American aquatic and semi-aquatic Hemiptera. Proceedings of the Entomological Society of Washington 10: 173-215.

Kirkaldy, G. W. 1898. On the nomenclature of the Europen subgenera of Corixa, Geoff. (Rhynchota.). Entomologist 31: 252-253.

Kleerekoper, H. 1955. Limnological observations in northeast Rio Grande do Sul, Brazil. Archiv für Hydrobiologie 50: 553-567.

Maltchik, L.; Rolon, A. S.; Guadagnin, D. L. \& C. Stenert. 2004. Wetlands of Rio Grande do Sul, Brazil: a classification with emphasis on plant communities. Acta Limnologica Brasiliensia 16: 137-151.

Melo, A. L. \& N. Nieser. 2004. Faunistical notes on aquatic Heteroptera of Minas Gerais (Brazil): an annotated list of Gerromorpha and Nepomorpha collected near Januária. Lundiana 5: 43-49.

Moreira, F. F. F.; Barbosa, J. F.; Ribeiro, J. R. I. \& V. P. Alecrim. 2011. Checklist and distribution of semiaquatic and aquatic Heteroptera (Gerromorpha and Nepomorpha) occurring in Brazil. Zootaxa 2958: 1-74.

Morrone, J. J.; Mazzucconi, S. A. \& A. O. Bachmann. 2004. Distributional patterns of Chacoan water bugs (Heteroptera: Belostomatidae, Corixidae, Micronectidae and Gerridae). Hydrobiologia 523: 159-173.

Neri, D. B.; Kotzian, C. B. \& A. E. Siegloch. 2005. Composição de Heteroptera aquáticos e semi-aquáticos na área de abrangência da U.H.E. Dona Francisca, RS, Brasil: fase de pré-enchimento. Iheringia, Série Zoologia 95: 421-429.

Nieser, N. 1970. Corixidae of Suriname and the Amazon, with records of other Neotropical species. Studies on the Fauna of Suriname and other Guyanas 12: 43-70.

Nieser, N. 1977. A revision of the genus Tenagobia Bergroth (Heteroptera: Corixidae). Studies on Neotropical Fauna and Environment 12: 156.

Nieser N. 2002. Guide to aquatic Heteroptera of Singapore and Peninsular Malaysia. IV. Corixoidea. Raffles Bulletin of Zoology 50: 263-274.

Nieser, N. \& A. L. Melo. 1997. Os Heterópteros Aquáticos de Minas Gerais. Guia Introdutório com Chave de Identificação para as Espécies de Nepomorpha e Gerromorpha. Belo Horizonte. Editora Universidade Federal de Minas Gerais. 177 p.

Nieser, N. \& P. P. Chen. 2006. Two new genera and a new subfamily of Micronectidae (Heteroptera, Nepomorpha) from Brazil. Denisia 19: 523-534.

Pelli, A.; Nieser, N. \& A. L. Melo. 2006. Nepomorpha and Gerromorpha (Insecta: Heteroptera) from the Serra da Canastra, southwestern Minas Gerais State, Brazil. Lundiana 7: 67-72.

Pereira, D. L. V.; Melo, A. L. \& N. Hamada. 2007. Chaves de identificação para famílias e gêneros de Gerromorpha e Nepomorpha (Insecta: Heteroptera) na Amazônia Central. Neotropical Entomology 36: 210-208. 
Pereira, D. L. V. \& A. L. Melo. 2007. Aquatic and semiaquatic Heteroptera (Insecta) from Pitinga, Amazonas, Brazil. Acta Amazonica 37: 643-648. Ribeiro, J. R. I.; Moreira, F. F. F.; Alecrim, V. P.; Barbosa, J. F. \& J. L. Nessimian. 2009. Espécies de heterópteros dulciaquícolas (Hemiptera, Heteroptera, Gerromorpha e Nepomorpha) registradas no Estado do Rio de Janeiro, Brasil. Arquivos do Museu Nacional 67: 303-312. Ruffinelli, A. \& A. A. Pirán. 1959. Hemípteros heterópteros del Uruguay.
Boletin de La Facultad de Agronomia de Montevideo 51: 1-60.

Souza, M. A. A.; Melo, A. L. \& G. J. C. Vianna. 2006. Heterópteros aquáticos oriundos do Município de Mariana, MG. Neotropical Entomology 35: 803-810.

Vianna, G. J. C. \& A. L. Melo. 2003. Distribution patterns of aquatic and semi aquatic Heteroptera in Retiro das Pedras, Brumadinho, Minas Gerais, Brazil. Lundiana 4: 125-128.

Received 20/5/2011; accepted 25/5/2012

Editor: Daniela Maeda Takiya 